\title{
1 Bond Behaviour of Oil Palm Broom Fibres in Concrete \\ 2 for Eco-friendly Construction
}

3 Author 1

4 Momoh, Emmanuel Owoichoechi

$5 \mathrm{MSc}(\mathrm{ENG})$, MSc, REng (COREN), MNSE, MNICE, AFHEA

6 r01eom18@abdn.ac.uk

7 https://orcid.org/0000-0003-3432-1366

8

9 Author 2

10 *Osofero, Adelaja Israel

11 PhD (DIC), CEng MICE, FHEA

12 aiosofero@abdn.ac.uk

13 https://orcid.org/0000-0002-5476-5979

14

Author 3

16 Menshykov, Oleksandr

$17 \mathrm{CSc}(\mathrm{PhD})$, DSc, FHEA

18 o.menshykov@abdn.ac.uk

19 https://orcid.org/0000-0003-2869-3307

(All authors)

23 School of Engineering, University of Aberdeen, King's College, Aberdeen, AB24 3UE, United

24 Kingdom

${ }^{*}$ Corresponding Author: Osofero, Adelaja Israel

27 Room 265, Fraser Noble Building,

28 School of Engineering,

29 University of Aberdeen,

30 King's College, Aberdeen,

31 United Kingdom.

$32+44(0) 1224274255$ 
Abstract

39

Global awareness towards climate changes and sustainability has attracted research into the use of natural materials in construction. Recent studies on the ribs of the leaflets of the oil palm tree - Oil Palm Broom Fibres (OPBF), reported impressive physico-mechanical properties. However, information on their bond behaviour with cementitious matrices is presently lacking. This study investigates the bond strength of single and combined OPBF in concrete through direct pull-out tests. Maximum bond strengths of 1.16, 0.95 and $0.82 \mathrm{MPa}$ were recorded at 28, 56 and 112 days respectively. The influence of age of sample and diameter of OPBF tendons on bond strength was observed. Images obtained from scanning electron microscopy reveal embrittlement of fibre surfaces by cement matrix. Finite element modelling of the pull-out behaviour was also carried out using ABAQUS. The potential use of OPBF combined in the form of tendons as longitudinal reinforcement in concrete for lightly loaded structural elements is environmentally friendly and can reduce construction cost.

Keywords: Concrete technology \& manufacture; Developing countries; Strength \& testing of materials. 
$64 \sigma_{b} \quad$ is the bond strength

$65 \quad \sigma_{28} \quad$ is the bond strength at 28 days

$66 \quad \sigma_{56} \quad$ is the bond strength at 56 days

$67 \quad \sigma_{112}$ is the bond strength at 112 days

$68 P \quad$ is maximum pull-out load

$69 d_{b} \quad$ is the diameter of tendon/fibre cross-section

$70 \quad L_{b} \quad$ is the embedded fibre/tendon length

$71 \sigma^{\prime} \quad$ is the nominal traction vector

$72 \sigma^{\prime}{ }_{i} \quad$ is the contact traction in a specified direction

$73 \sigma_{i}^{D} \quad$ is the contact traction after damage initiation

$74 \quad D \quad$ is the scalar damage parameter

$75 d_{i} \quad$ is the direction unique scalar damage variable

$76 K \quad$ is the stiffness matrix

$77 \delta \quad$ is the separation caused by traction

$78 \delta_{i} \quad$ is the separation in a specified direction

$79 \delta_{i}^{f} \quad$ is the complete failure separation in a specified direction

$80 \mathrm{~T}_{\mathrm{e}} \quad$ is the element thickness

$81 \varepsilon \quad$ is elemental strain

$82 \quad F \quad$ is the number of fibres per tendon

$83 f_{c} \quad$ is the compressive strength of concrete

$84 E \quad$ is the Young's Modulus

$85 \quad v \quad$ is the Poisson ratio

86 


\subsection{Introduction}

The flexural capacity of plain concrete is generally low and inadequate for most structural application, hence the incorporation of steel in the form of longitudinal reinforcement. Although steel reinforcement possesses good compatibility with concrete and steel-reinforced concrete shows improved mechanical properties such as tensile strength, shear strength, ductility and toughness, it is expensive. Carbon dioxide emissions caused by the production of steel and steel-reinforced concrete are also harmful to the environment. The continuous increase in costs associated with the provision of reinforced concrete infrastructures has also made access to decent housing increasingly difficult in developing countries. In sub-Saharan Africa for example, prevailing factors such as high population growth rates, extreme poverty level among citizens, lack of well-structured housing credit system and inflation have caused serious housing deficits (Bah, et al., 2018). The need for the importation of refined construction materials (e.g. steel), has also resulted in high cost of construction thereby creating the need to search for alternative indigenous building materials.

Unlike steel, which is imported after the process of mining iron ore and subsequent refinement, fibrous plants are readily available in developing countries in the tropics, can easily be replanted and replenished, are considerably more economical to process and are environmentally friendly. The extraction of such fibres is carried out through low energy-intensive procedures such as either cutting the desired plant parts or merely obtaining the plant residues and wastes and subjecting them to retting. The fibres are then usually extracted by manual mechanical separation or by using a decorticator (Onuaguluchi and Banthia, 2016). For instance, a study of energy required for producing conventional reinforcement for concrete showed that 50 times more energy is required for producing conventional steel reinforcement than is required for bamboo reinforcement (Seixa, et al., 2014). Furthermore, plant fibres possess advantages such as low carbon footprint, low-cost, lightweightiness, toughness, thermal insulation, improved acoustic insulation, high recyclability, biodegradability and non-toxicity to the ecosystem (Ramakrishna and Sundararajan, 2005; Ardanuy, et al., 2015; Claramunt, et al., 2016; Agopyan, et al., 2005; Page, et al., 2017). Therefore, the need for researchers and engineers to focus on the possibility of developing low-cost indigenous construction materials from region-specific fibrous plants cannot be overemphasised. 
122 Currently, bamboo stems are the most-studied plant material for longitudinal reinforcement of lightly

123 loaded concrete elements. Ghavami (1995) determined some physical and mechanical properties of

124 bamboo (Dendrocalamus giganteus) strips which they were treated with Negrolin and sand and then used to reinforce two $300 \times 120 \times 3000 \mathrm{~mm}$ concrete beams. A comparison between the flexural capacity of the unreinforced concrete beam, the bamboo-reinforced concrete beams and the steelreinforced concrete beam was carried out. At the recommended bamboo reinforcement ratio of $3 \%$, the bamboo reinforced beam recorded a maximum flexural strength of about $400 \%$ and $60 \%$ of that of the unreinforced beam and steel-reinforced beam (of 0.78 reinforcement ratio) respectively. Bond strength between the concrete and the bamboo strips were also reported as 0.52 and $0.92 \mathrm{MPa}$ for untreated and treated strips respectively after a bond pull out test. The compressive strength of the concrete was reported as $19 \mathrm{MPa}$ and was obtained by testing $300 \times 150 \mathrm{~mm}$ cylinders to failure.

Ganesan et al. (2018) studied the behaviour of 3 full-scale bamboo-reinforced one-way spanning concrete wall panels. The bamboo strips (obtained from Bambusa bambos) were varnished and sandblasted prior to their use in M20 concrete. The spacing of the reinforcement strips was carried out according to the requirements of the National Building Code of India-Part 6 (NBC 2016). After 28 days of curing, the wall panels were tested under pinned-end conditions at top and bottom. Loading was applied in a uniformly distributed manner with an eccentricity to simulate real-life scenario. With wall resistance between $700-850 \mathrm{kN}$, the study recommended bamboo reinforced wall panels as viable and sustainable option to steel-reinforced ones. In a similar study by Mali and Datta (2018), the use of bamboo-reinforced concrete slab elements was recommended for use as lightly loaded roofing members for low-cost housing.

Muhtar, et al. (2019) improved slip resistance and bond strength of bamboo (Dendrocalamus asper) reinforcement in concrete using hose clamps. The samples consisted of an unreinforced concrete beam, an $8 \mathrm{~mm}$ steel-reinforced concrete beam and twenty-two $75 \times 150 \times 1100 \mathrm{~mm}$ bambooreinforced concrete beams. The bamboo strips were water-proofed by Sikadur $\AA-752$ coating after which hose clamps were installed at predetermined distances along the reinforcement strips and a second coating of Sikadur® -752 applied over the whole length. Ultimate failure load in flexure of the bamboo-reinforced concrete (of reinforcement ratio $=4.0 \%$ ), with hose clamps fixed at $20 \mathrm{~mm}$ spacing 
around the strips, was greater than the one for control steel-reinforced beam (of reinforcement ratio $=$ $0.89 \%)$ by about $26 \%$.

152 Like bamboo, the ribs of the leaflets of the oil palm tree, otherwise known as oil palm broom fibres 153 (OPBF), have attracted research attention recently due to their impressive mechanical properties 154 (Momoh and Dahunsi, 2017; Momoh and Osofero, 2019; Momoh, et al., 2020). Average tensile strength of OPBF was reported as $389 \mathrm{MPa}$, density ranged from $450-840 \mathrm{~kg} / \mathrm{m}^{3}$ and 24 hours water absorption was reported as $44.7 \%$. The tensile strength to weight ratio of OPBF is about 5 times that of steel, it does not rot easily and has low affinity for water, unlike other vegetable fibres (Momoh, et al., 2020). An illustration of different types of fibres from the oil palm tree is presented in the review by Momoh and Osofero (2020). Oil palm fibres such as OPBF can be found in 42 countries spanning the continents of Asia, Africa and South America which totals a land area of about 17 million hectares. Countries with high palm oil production have been reported to face difficulties with managing waste biomass generated from oil palm cultivation and processing activities (Khatun, et al., 2017; Momoh and Osofero, 2020). Current global oil production from oil palm is estimated as 78 million metric tonnes per year with Malaysia and Indonesia being top producers, while Nigeria and Ghana share about $19.5 \%$ of global oil palm plantation (Khatun, et al., 2017). Coincidentally, these regions have been continuously plagued with housing deficits. Therefore, the availability of oil palm fibres such as OPBF has attracted research interests for their use in the development of affordable and sustainable building materials in these regions.

A preliminary study on the incorporation of discrete $(50 \mathrm{~mm}$ long) OPBF in concrete was carried out by Momoh and Osofero (2019). The area under the monotonic load-deflection curves of $100 \times 100 \times 500$ mm samples investigated in the study showed improvement in energy absorption by over $300 \%$. Although no significant improvement in compressive strength was recorded, the improvement in toughness implies a more ductile failure for the OPBF-concrete as against the inherent sudden brittle failure of plain concrete. An enhancement in splitting tensile strength of $1.2 \%$ at 28 days was also reported in the same study (Momoh and Osofero, 2019).

OPBF like other vegetable fibres are naturally functionally graded and anisotropic with mechanical properties varying in both the longitudinal and radial directions. However, structural reinforcements can be developed from the vegetable fibres if combined in the form of tendons (Momoh and Dahunsi, 
2017). Figure 1.1 illustrates the locations of OPBF on an oil palm leaf and some extracted OPBF tied

180

181

182

183

184

185

186

187

188

189

190

191

192

193

194

195

196

197

198

199

200

201

202

203

204

205

206 into broom units. The OPBF are the ribs of the leaflets of the oil palm tree usually extracted by scraping off the leaflets from the ribs with the aid of a hand knife. The fibres are then tied as broom units (Figure 1.1 c) with each unit consisting of between 500-1000 fibres to be sold in local markets for approximately 0.1 USD per unit and even for a lesser amount in rural areas.

The major factors responsible for the improvement of mechanical properties of fibre-reinforced composites are the mechanical properties of the reinforcing fibres, shape and geometry of the fibres, fibre dosage, fibre orientation and fibre-matrix adhesion. Mechanical properties of some vegetable fibres used for reinforcing cementitious composites are presented in Table 1.1. Due to the relatively high tensile strength of vegetable fibres, the failure mode of most natural fibre-reinforced cementitious composites is characterised by fibre pull-out from the matrix. A well-established method for the characterisation of fibre/matrix interface is the single fibre pull-out experiment (Naik, et al., 2019; Soulioti, et al., 2013) where an axial force is applied unto the tip of a fibre in order to pull it out of a host matrix.

Studies on the bond behaviour of concrete-steel fibres (Soulioti, et al., 2013), concrete-Fibre Reinforced Polymer bars (Zenon and Pilakoutas, 2004), polypropylene-cement matrix (Singh, et al., 2004) and natural fibre-cement matrix (Naik, et al., 2019; Ramakrishna and Priyadharshini, 2018; Ferreira, et al., 2018) show that transfer of forces from fibres or reinforcement bars onto matrix is dependent on three mechanisms: chemical adhesion, mechanical anchorage and frictional force (Ramakrishna and Priyadharshini, 2018; Ferreira, et al., 2016). Other influential parameters include concrete cover, bar embedded length, bar size and yield strength (ACI 408R-03, 2003; Issa and Masri, 2015). Axial force applied to a reinforcement bar creates both tangential and parallel stress components along the bar-concrete contact surface. The parallel stress component is known as bond stress (Hadi, 2008). Bond force, therefore, is the force required to move a bar parallel to its length with respect to the surrounding matrix. Knowledge of bond stress, usually obtained from pull-out tests, is required for understanding the transition zone, the resistance to crack propagation and also for predicting composite mechanical performance (Savastano and Agopyan, 1999). Although the pull-out test procedure results in higher values of bond strength than is possible to achieve in practice, for 
example where maximum bond depends on cover thickness, it offers an economic and simple procedure (Zenon and Pilakoutas, 2004; Osofero, et al., 2015).

209

While most of the natural fibres presented in Table 1.1 are superior to steel in terms of tensile strength-to-weight ratio, their range of Young's modulus which is about $1.4-22 \%$ of the Young's modulus of steel may pose serviceability concerns in structural design. This entails devising a

212 different design approach with special recommendations. Consequently, the need to adequately understand their bond behaviour with cementitious matrices becomes a fundamental preliminary task.

Table 1.1. Mechanical properties of some vegetable fibres used in cement composites

\begin{tabular}{|c|c|c|c|c|}
\hline $\begin{array}{l}\text { Vegetable } \\
\text { Fibre }\end{array}$ & $\begin{array}{c}\text { Average } \\
\text { tensile } \\
\text { strength } \\
\text { (MPa) }\end{array}$ & $\begin{array}{c}\text { Average } \\
\text { Young's } \\
\text { modulus } \\
\text { (GPa) }\end{array}$ & $\begin{array}{l}\text { Density } \\
\left(\mathrm{kg} / \mathrm{m}^{3}\right)\end{array}$ & Reference \\
\hline OPBF & 389.5 & 9 & $450-840$ & Momoh et al. (2020) \\
\hline Jute & 250 & 44 & - & Ferreira et al. (2016) \\
\hline Sisal & 400 & 19 & - & Silva et al. (2011) \\
\hline Date Palm Fibre & 93.4 & 2.7 & 720 & $\begin{array}{c}\text { Hamid and } \\
\text { Abdelmadjid (2016) }\end{array}$ \\
\hline Coconut & $95-118$ & 2.8 & 1177 & $\begin{array}{l}\text { Pacheco-Torgal and } \\
\text { Jalali (2011) }\end{array}$ \\
\hline Wheat straw & 47 & 3.9 & - & Naik et al. (2019) \\
\hline Piassava & 143 & 5.6 & 1054 & $\begin{array}{c}\text { Pacheco-Torgal and } \\
\text { Jalali (2010 }\end{array}$ \\
\hline Bamboo (D. asper) & 126.7 & 17 & - & Muhtar et al. (2019) \\
\hline Bamboo (B. arundinacea) & 200 & 8 & 1125 & Malli and Datta (2018) \\
\hline Bamboo (B. vulgaris) & 141 & 13 & 720 & Ghavami (1995) \\
\hline Polypropylene & 250 & 2 & 913 & $\begin{array}{l}\text { Pacheco-Torgal Jalali } \\
\text { (2010) }\end{array}$ \\
\hline CFRP & $>15$ & 115 & - & $\begin{array}{c}\text { Zenon and Pilakoutas } \\
\text { (2004) }\end{array}$ \\
\hline GFRP & $>1000$ & 45 & - & $\begin{array}{c}\text { Zenon and Pilakoutas } \\
\text { (2004) }\end{array}$ \\
\hline Steel & $400^{*}$ & 207.7 & 8700 & Muhtar et al. (2019) \\
\hline
\end{tabular}

\subsection{Bond behaviour of natural fibres in cementitious matrix}

216 Bond pull-out curves for most natural fibres in cement composites are characterised by three main

217 stages, namely: perfectly-bonded stage, partially-debonded stage and fully-debonded stage (Wan and

218 Parris, 2016). Figure 1.2 illustrates a typical pull-out response of a single OPBF from a concrete 
matrix (Momoh and Osofero, 2019). The response at the perfectly bonded stage is almost linear.

Debonding begins at the region where the fibre meets the matrix and travels through the matrix along the fibre-matrix interface, marking the onset of a non-linear response. As the pull-out force on the fibre becomes greater than the bond stress, the slope of the curve flattens out or sometimes drops abruptly at complete debonding. Pull-out response for natural fibres after complete debonding from their matrix can be classified as either: slip-hardening, constant friction or slip-softening (Naik, et al., 2019). At complete debonding, chemical adhesion expires, and the response becomes predominantly due to mechanical interlocking and friction. Major factors affecting post-debonded stage response are purity of fibre surface, roughness of fibre surface, shape of fibre, embedded fibre length and fibre/matrix strength ratio.

For vegetable fibres in cementitious matrix, the degradation of fibre surface due to alkali attack causes slip softening, as the fibre-matrix interface becomes separated by an organic layer (Wan and Parris, 2016; Wei and Meyer, 2015). Such layer creates a lubricating effect thereby facilitating slip. Consequently, chemical treatments for enhancing the resistance of natural fibres to surface deterioration by alkali have been successful in previous research (Wei and Meyer, 2014). The area under the bond stress versus slip curve is the energy required for complete pull out of the fibre from the matrix. It follows from Figure 1.2 that the area under the curve from the onset of loading to the end of the partially bonded stage is the energy dissipated in debonding the fibre from the matrix. In other words, it is referred to as debonding energy while the area under the fully-debonded stage is the pullout energy (Naik, et al., 2019).

Due to high variability in physico-mechanical properties of natural fibres and different experimental procedures, different values of embedded lengths are recommended. For example, different optimum embedded length for sisal fibres was determined by previous studies as $30 \mathrm{~mm}$ (Morrissey, et al., 1985) and $40 \mathrm{~mm}$ (Silva, et al., 2011). Morrissey, et al. (1985) prepared and tested a total of 210 samples of sisal fibres embedded in ordinary Portland cement matrix of water-cement ratio of 0.4 (by weight). The mean cross-sectional radius of the fibres was recorded as $0.21 \mathrm{~mm} \pm 0.04 \mathrm{~mm}$ and they were embedded in the matrix at 10,15, 20,30,40,50 and $60 \mathrm{~mm}$ and pulled out of the matrix at a displacement control rate of $10 \mathrm{~mm} /$ minute. Silva, et al. (2011) on the other hand, embedded 6 samples of sisal fibres with similar cross-sections in a mortar matrix mix of 1:1:0.4 binder/sand/water 
(by weight) respectively. The specific weight of the river sand used was 2.67 . The binder consisted of

Portland cement CPII F-32 and 5\% (by volume) of wollastonite as micro reinforcement and a naphthalene plasticiser to enhance the tensile strength and rheology of the matrix. The fibres were embedded at lengths ranging from $10-40 \mathrm{~mm}$ and pulled out at a speed of $0.1 \mathrm{~mm} / \mathrm{min}$. The loading rate applied in testing the samples makes comparison of results obtained from the study with that from the study of Morrissey, et al. (1985) difficult. Other recommendations of optimum embedded length obtained from pull out test of natural fibres in cement/sand mortar include, $40 \mathrm{~mm}$ for date palm fibres with a cross-sectional diameter of $0.55 \mathrm{~mm}$ and embedded in cement-sand matrix (Hamid and Abdelmadjid, 2016), $20 \mathrm{~mm}$ for wheat straw with cross-sectional diameter of $1.14 \mathrm{~mm}$ and embedded in cement-clay matrix (Naik, et al., 2019) and $25 \mathrm{~mm}$ for sisal and coir with cross-sectional diameters of $0.13 \mathrm{~mm}$ and $0.40 \mathrm{~mm}$ respectively, embedded in cement-sand matrix (Ramakrishna and Priyadharshini, 2018). Experimental assessment of bond behaviour of jute fibres having embedded lengths of $5 \mathrm{~mm}$ and $10 \mathrm{~mm}$ in (1:0.5:0.4) cement/sand/water mortar reported a bond strength ranging between 0.17-0.46 MPa with fibre pull-out as the major failure mode (Ferreira, et al., 2016). This is similar to $0.36-0.38 \mathrm{MPa}$ range reported for sisal fibres in (1:1:0.4) cement/sand/water matrix (Silva, et al., 2011), 0.23-0.3 MPa for wheat straw in (1:1:1) cement/clay/water (Naik, et al., 2019) and 0.05$0.33 \mathrm{MPa}$ for date palm fibres in (1:3:0.55) cement/sand/water matrix (Hamid and Abdelmadjid, 2016). In addition, bond strength variability with age (for up to 28 days) was observed in (Ramakrishna and Priyadharshini, 2018) to increase for sisal fibres, but decreased for coir.

Bond pull-out behaviour for plant parts of larger dimensions, like bamboo culms, in concrete is similar to that of smaller fibres. Varying bond strength values for bamboo in concrete were also reported; e.g., $0.41 \mathrm{MPa}$ for an embedded length of $300 \mathrm{~mm}$ in $12 \mathrm{MPa}$ concrete (Nindyawati and Umniati, 2016) and $1.74 \mathrm{MPa}$ at an embedded length of $150 \mathrm{~mm}$ in $30 \mathrm{MPa}$ (cube strength) concrete (Sakaray, et al., 2012). In another study, a bond strength value of between $0.14-1.4 \mathrm{MPa}$ was reported for surface-treated bamboo at an embedded length of $100 \mathrm{~mm}$ in $20 \mathrm{MPa}$ (cube strength) concrete (Mali and Datta, 2019). Ghavami (1995) reported $0.52 \mathrm{MPa}$ for an embedded length of $100 \mathrm{~mm}$ in $19 \mathrm{MPa}$

274 (cylinder strength) concrete, while Kute and Wakchaure (2013) reported bond strength values of 0.73 - 0.9 MPa for untreated bamboo at an embedded length of $150 \mathrm{~mm}$ in $20 \mathrm{MPa}$ (cube strength) concrete. These indicate that bond strength increases with an increase in both the compressive strength of concrete and embedded length of the fibre. Similar to smaller vegetable fibres behaviour, 
278 the predominant failure mode is debonding and pull-out of the bamboo fibres. It is important to note,

279 however, that the bond behaviour of single small fibres in a cementitious matrix may be different from

280 that of combined fibres or typical single reinforcement bars.

281 Although OPBF are reported as being superior to steel reinforcement in terms of tensile strength-to-

282 weight ratio and may be combined in the form of tendons for the purpose of reinforcing concrete

283 (Momoh et al., 2020), research interest in OPBF is recent and a study on their bond behaviour with

284 concrete is non-existent at the moment. Therefore, bond behaviour of single OPBF and combined

285 OPBF (in form of tendons) was investigated. In addition, the effect of age of the composite on bond

286 strength was observed. Finally, a 3D-nonlinear finite element model capable of simulating the

287 experimental bond-slip relationship between OPBF and concrete was carried out. This study will

288 enhance decision-making in the design and use of the natural fibres for reinforcing load-bearing

289 cementitious elements.

$290 \quad 2 . \quad$ Materials and Method

$291 \quad 2.1 \quad$ Experimental study

292 Cement, coarse and fine aggregates were obtained from Jewson Ltd, Aberdeen, UK, while OPBF 293 were obtained from Rice and Spice, Aberdeen, UK, in the form of broom units. The OPBF were not

294 subjected to any form of pre-treatment. From trial mixes, an average 28-days compressive strength of $29530 \mathrm{MPa}$ (cylinder strength) was achieved for a mix ratio of 1:1.5:3 cement, fine aggregate and coarse 296 aggregate, respectively (by volume), at a water-cement ratio of 0.52 and a slump value of $95 \mathrm{~mm}$.

297 This grade of concrete is adequate for construction of residential buildings (Singh and Scanlon, 2013).

298 Particle size grading of aggregates was carried out according to ASTM C136/C136M (2014). The fine 299 aggregate used was river sand while the coarse aggregate was naturally weathered igneous rock 300 (pea gravel). Constituents of concrete used, and particle size distribution curves are presented in 301 Figure 2.1. Specific gravities of fine aggregate classified as medium sand and coarse aggregate 302 classified as fine grave/ were 2.55 and 2.62, respectively. General-purpose cement (Blue circle ${ }^{\circledR}$ ) was 303 used as the binder. Concrete mixing procedure commenced with the pouring of the required amount 304 of water in a 25-litres electrically-powered mixing drum, followed by the addition of respective 305 quantities of aggregates. 
Samples were prepared for both single fibre pull-out and combined fibre pull-out testing in order to understand possible differences between the bond behaviour of single OPBF and combined OPBF tendons. For the latter, OPBF were combined in the form of twisted tendons where individual fibres were wound around themselves (in a helical shape) in the same direction and held in position radially by aluminium wires of $1 \mathrm{~mm}$ diameter (see Figure 2.2). Like other plant fibres, the flexibility of OPBF is dependent on the moisture content. Moisture content of the OPBF was determined according to the requirements of ASTM D4442 (2016) as $9.81 \%$ and density as $840 \mathrm{~kg} / \mathrm{m}^{3}$. Details of physical and mechanical properties of OPBF are presented in a previous study by the authors (Momoh et al. 2020). Winding of OPBF around themselves to form tendons was carried out to the extent to which the flexibility of individual fibres could allow without breakage. Approximate distances along the length of respective tendons for each complete cycle of winding were measured as $30 \mathrm{~mm}, 50 \mathrm{~mm}, 70 \mathrm{~mm}$, $100 \mathrm{~mm}$ and $140 \mathrm{~mm}$ for 2, 3, 4, 5 and 6 fibres respectively. The OPBF tendons were then cut into lengths of $200 \mathrm{~mm}$, after which one end of each tendon was dipped in epoxy glue to form a thick bulb of glue around it. This was done to prevent the tendons from being damaged by the grips of the universal testing machine. A thin layer of epoxy was then applied around the tendons from the glue bulb, down to $80 \mathrm{~mm}$ before tendon-end such that $80 \mathrm{~mm}$ of each tendon was embedded in the concrete matrix. This was done to prevent moisture-induced premature weakening of fibres having direct contact with moisture during curing. Weakening of the tendons would result in tensile failure of tendon itself instead of bond failure with concrete during pull-out test. The cross-section of the opposite end of the tendons were smeared with epoxy glue and the aluminium wires were removed after the glue had set. Figure 2.3 presents a schematic diagram of the test set up.

327 Cubic moulds of $100 \mathrm{~mm}$ were placed on a vibrating table and filled with concrete. The OPBF tendons were inserted in the fresh concrete to an embedded length of $80 \mathrm{~mm}$ and held in position by hand as the concrete was vibrated. At the end of the vibration, the sample was left to air-cure at room temperature for 24 hours after which they were demoulded and immersed in a curing tank with water level just at the top level of the concrete (Figure 2.4). Submerging of whole sample was avoided to prevent excessive soaking (and possible weakening) of OPBF tendon. At the specified test dates, the samples were removed from the water, left to stand for about 2 hours and wiped dry with a soft paper towel. Testing was carried out on a Hounsfield universal testing machine (Model H1OKS) with a 3kN 
337

load cell in displacement control at $2.5 \mathrm{~mm} / \mathrm{min}$. Uniform bond between OPBF and concrete was assumed, and bond strength was calculated according to Eqn 2.1.

$\sigma_{b}=\frac{P}{\pi d_{b} L_{b}}$

where $\sigma_{b}$ is the bond strength, $P$ is maximum pull-out load, $d_{b}$, is the diameter of tendon cross-section and $L_{b}$ is the embedded fibre/tendon length. The cross-sectional area of each OPBF-tendon was assumed to be circular and was measured using a digital veneer calliper with a precision of $0.01 \mathrm{~mm}$.

A total of fifty-four (54) specimens were prepared, cured and tested. Testing was carried out at 28, 56 and 112 days of curing. Sample designation is explained as: XF-YYY such that $X$ stands for the number of fibres in the tendon, $\mathrm{F}$ stands for fibres and $\mathrm{YYY}$ stands for the age of sample at testing (in days). For example, $6 \mathrm{~F}-028$ refers to an OPBF tendon consisting of 6 fibres and tested at 28 days in direct bond-pull out. Similarly, 2F-112 is an OPBF tendon consisting of 2 fibres and tested at 112 days. Sample preparation and testing were carried out in the cement and materials laboratory of the School of Engineering, University of Aberdeen, UK.

Scanning Electron Microscopy (SEM) images of OPBF surface before insertion in the concrete matrix and after pull-out were obtained using a CarlZeiss GeminiSEM 300VP scanning electron microscope. About 20nm-thick carbon coating was applied over the OPBF surfaces and followed by approximately $10 \mathrm{~nm}$-thick sputter coating of gold/palladium alloy $(60 \% \mathrm{Au}$ and $40 \% \mathrm{Pd})$ in order to enhance the conductivity of the samples. SEM was performed using the facilities at the Aberdeen Centre for Electron Microscopy, Analysis and Characterisation (ACEMAC), University of Aberdeen, UK.

\subsection{Modelling of bond behaviour}

Modelling of reinforced concrete behaviour can be achieved through three different approaches: distributed, embedded and discrete, with the first two approaches assuming perfect bonding between matrix and reinforcement (Issa and Masri, 2015; Khalfallah and Ouchenane, 2007). Perfect bonding is, however, difficult to realise in practice, hence the use of discrete approach for modelling of composites (Jendele and Cervenka, 2006).

An efficient finite element methodology to represent interfacial deterioration is surface-based cohesive contact modelling (Alizadeh, 2019; Farzad, et al., 2014; Omar, et al., 2014). Surface-based cohesive 
models are suitable for problems where interfacial strength is relatively weak compared to the material properties of the bodies in contact (Camanho and Dávila, 2002) and where the interfacial thickness is negligible (Farzad, et al., 2014). Cohesive contact modelling can also simulate the progression of damage without the need to define an initial crack, unlike in classical fracture mechanics modelling (Campilho, et al., 2011; Ali, et al., 2019). The surfaces in contact can also stick after separation (Bendetti and Aliabadi, 2013). Modelling of contact between the surfaces uses the traction-separation constitutive relationship and contact is defined as a surface interaction property rather than a material property (Farzad, et al., 2014). The cohesive surface model has reduced meshsensitivity and does not require the mass of the materials since it is defined as an interface property, thereby reducing computational efforts (Ramamurthi, et al., 2013). Although the cohesive models in ABAQUS were originally developed for the simulation of delamination in composites (Ali, et al., 2019; Pereira, et al., 2015), their appropriateness for simulation of pull-out behaviour has been demonstrated in (Khalfallah and Ouchenane, 2007; Serpieri, et al., 2015; Fantilli and Vallini, 2007).

Surface-based cohesive contact method was employed in this study to simulate the bond behaviour between OPBF and concrete. A general elastic constitutive matrix that relates nominal stresses to nominal strains of an element of finite thickness across the interface can be defined as Eqn 2.2 (Farzad, et al., 2014):

$\sigma^{\prime}=\left\{\begin{array}{l}\sigma^{\prime}{ }_{n} \\ \sigma^{\prime}{ }_{s} \\ \sigma^{\prime}{ }_{t}\end{array}\right\}=\left[\begin{array}{lll}K_{n n} & K_{n s} & K_{n t} \\ K_{n s} & K_{s s} & K_{s t} \\ K_{n t} & K_{s t} & K_{t t}\end{array}\right]\left(\begin{array}{c}\delta_{n} \\ \delta_{s} \\ \delta_{t}\end{array}\right\}=K \delta$

where $\sigma^{\prime}$ is the nominal traction vector, $K$ is the stiffness matrix and $\delta$ is the corresponding separation each having components in the normal direction (subscript $n$ ) and the two shear directions (subscripts $s$ and $t$ ). The nominal stresses and strains are the force components divided by original area and separations divided by original thickness, respectively, at each integration point. For a 3dimensional cohesive element with thickness $T_{e}$ and strains $\varepsilon$, the separations can be expressed as:

$$
\delta_{n}=\varepsilon_{n} T_{e}, \quad \delta_{s}=\varepsilon_{s} T_{e}, \quad \delta_{t}=\varepsilon_{t} T_{e} .
$$

In ABAQUS, constitutive thickness of the cohesive surface is assumed to have a unit value (Ramamurthi, et al., 2013). For pure normal separation where cohesive forces in the shear directions are zero, and pure shear slip yields zero normal separation, Eqn 2.2 can be simplified and only 
$K_{n n}, K_{s s}$ and $K_{t t}$ are defined. For an isotropic material, the stiffness $K$ is used everywhere because the values in all directions are the same (Ramamurthi, et al., 2013).

391 Relative motion between the interacting surfaces can be chosen as "finite sliding", "infinitesimal sliding" or "small sliding". Small sliding interacting surface model was used in this study as it allows for relatively little sliding of one surface along the other, based on linearised approximations of the master surface per constraint. In addition, it is computationally less expensive than finite sliding, particularly for 3-dimensional contact modelling (ABAQUS, 2019). This means that an initial linear elastic bond behaviour (interface stiffness) ends at the maximum bond stress (damage initiation criterion) and is followed by degradation of interface stiffness (damage evolution criterion) (Sun and Jin, 2012). Damage initiation refers to the beginning of degradation of the cohesive response at a contact point by setting limits for the contact stresses and/or contact separations. Beyond the set limit, the process of degradation of interface bond commences.

The linear post-damage initiation softening response is defined for the degradation of interface stiffness using damage evolution criterion. Figure 2.5 shows a representation of a traction-separation response. The damage evolution law specifies a scalar damage parameter $D$ which evolves from 0 to 1 upon further loading after damage is initiated (Campilhoa, et al., 2008) such that:

Where, $\sigma_{i}^{D}$ is the contact stress after damage initiation and ${\sigma^{\prime}}_{i}$ is the contact traction at normal and shear directions ( $I$ ). For complete failure separation $\delta_{i}^{f}$ and maximum relative displacement $\delta_{i}^{\max }$, the irreversible, bilinear, softening behaviour represented in Figure 2.5 was developed by Camanho and Dávila (2002) and defined by Eqn 2.4.

$410 \quad \sigma^{\prime}{ }_{i}=\left\{\begin{array}{cl}K \delta_{i} & \leftarrow \delta_{i}^{\text {max }} \leq \delta_{i}^{o} \\ \left(1-d_{i}\right) K \delta_{i} & \leftarrow \delta_{i}^{o}<\delta_{i}^{\text {max }}<\delta_{i}^{f} \\ 0 & \leftarrow \delta_{i}^{\max } \geq \delta_{i}^{f}\end{array}\right.$

411 where $d_{i}$ is the direction unique scalar damage variable defined by Eqn 2.5

412

$d_{i}=\frac{\delta_{i}^{f}\left(\delta_{i}^{\max }-\delta_{i}^{o}\right)}{\delta_{i}^{\max }\left(\delta_{i}^{f}-\delta_{i}^{o}\right)} \quad d_{i} \in[0,1]$

413 For the model described beyond $\delta_{i}^{f}$ the interface becomes traction-free (i.e. are under no stress). 
414 The maximum stress criterion (Eqn 2.6) and the maximum separation criterion (Eqn 2.7) are the two 415 damage initiation criteria applied for the interface:

$416 \max \left\{\frac{\left\langle\sigma_{n}\right\rangle}{\sigma_{n}^{o}}, \frac{\sigma_{s}}{\sigma_{s}^{o}}, \frac{\sigma_{t}}{\sigma_{t}^{o}}\right\}=1$

$417 \max \left\{\frac{\left\langle\delta_{n}\right\rangle}{\delta_{n}^{o}}, \frac{\delta_{s}}{\delta_{s}^{o}}, \frac{\delta_{t}}{\delta_{t}^{o}}\right\}=1$

418 where $\sigma_{n}^{o}, \sigma_{s}^{o}$ and $\sigma_{t}^{o}$ are the peak values of the contact stress when the separation is either purely

419 normal to the interface or purely in the first and second shear direction, respectively. The same

420 definition applies to the peak values of contact separation $\delta_{n}^{o}, \delta_{s}^{o}, \delta_{t}^{o}$. Macaulay brackets \langle\rangle are used for the contact stress normal to the interface to emphasise that damage is not initiated by a purely compressive stress state (Omar, et al., 2014; Ramamurthi, et al., 2013; Campilho, et al., 2011).

\subsubsection{Finite Element modelling of OPBF-concrete bond}

Perfect bonding does not exist between OPBF and concrete, hence, the discrete approach of finite element modelling was employed. Three-dimensional modelling was used to simulate the pull-out behaviour of OPBF in concrete matrix. Interfacial deterioration during pull-out was modelled using surface-based cohesive contact modelling. The ability of model surfaces to stick is representative of bond behaviour between OPBF and concrete which does not deteriorate completely for the experimental pull-out distance. Concrete and OPBF were modelled using 8-node linear brick elements with reduced integration (C3D8R). Both concrete and OPBF dimensions were consistent with the physical pull-out samples with a circular cross-section assumed for the tendons: i.e., $100 \mathrm{x}$ $100 \times 100 \mathrm{~mm}$ for the concrete matrix and cross-sectional diameters of $1.20 \mathrm{~mm}, 2.10 \mathrm{~mm}, 3.00 \mathrm{~mm}$, $3.10 \mathrm{~mm}, 3.70 \mathrm{~mm}$ and $3.82 \mathrm{~mm}$ for $1 \mathrm{~F}, 2 \mathrm{~F}, 3 \mathrm{~F}, 4 \mathrm{~F}, 5 \mathrm{~F}$ and $6 \mathrm{~F}$ tendons respectively. Each tendon was $200 \mathrm{~mm}$ in length.

The $100 \mathrm{~mm}$ cubic homogeneous solid was assigned the material properties of the concrete as obtained from the experiments. Each cube model had a circular opening with a diameter corresponding to the respective OPBF-tendon and running through from the top centre-face to the bottom centre-face of the concrete model cube. OPBF-tendons were also modelled as homogeneous solids and assigned corresponding average elastic properties obtained from the experiments. Each 
441 (embedded length from experiment) of $80 \mathrm{~mm}$ was achieved. See Table 2.1 for material properties 442 used in the numerical models.

443 Concrete was taken as the master surface while OPBF tendon was taken as the slave surface. Two

444 boundary conditions were defined for the models: firstly, an "encastre" to rigidly fix the top of the 445 concrete cube and a "displacement" of $8 \mathrm{~mm}$ applied to the free end of the OPBF tendon in the pull-

446 out direction. This generated the force required to pull out the tendon from the concrete for the applied 447 displacement. The displacement was applied in small increments of $0.1 \mathrm{~mm}$ to avoid numerical 448 instability. Mesh sizes used were $5 \mathrm{~mm}$ and $10 \mathrm{~mm}$ in the length direction for the concrete and OPBF respectively. However, finer mesh size was used around the interaction region between the two materials in order to enhance the accuracy of the results. Coarser meshes were used for concrete region farther away from the OPBF in order to reduce computational time. From the experiments, over $60 \%$ loss in the bond stress was recorded at $20 \mathrm{~mm}$ slip of OPBF-tendons, hence a final separation distance $\delta_{i}^{f}$ of $20 \mathrm{~mm}$ was specified for the models. The problem was solved using ABAQUS' standard static procedure. Figure 2.6 presents visualisation of the finite element modelling of OPBF pull-out from concrete.

Table 2.1: Material properties used in bond pull out models

\begin{tabular}{lllll}
\hline Material & Compressive & Tensile & Youngs Modulus & Poisson's ratio \\
& strength & strength & $E(\mathrm{GPa})$ & $v$ \\
& $f_{c}(\mathrm{MPa})$ & $\mathrm{fy}(\mathrm{MPa})$ & & \\
\hline Concrete & 30 & -- & 25 & 0.15 \\
OPBF-tendon & -- & 389 & 9 & 0.4 \\
\hline
\end{tabular}

457

\section{Discussion of Results}

459 Table 3.1 and Figure 3.1 shows results (with standard deviations) of pull-out test of OPBF from 460 concrete. Sample failure was governed by tendon pull-out from concrete matrix. Average pull-out 461 curves of the samples are shown in Figures 3.1 (a,b,c) at 28, 56 and 112 days, respectively.

462 Generally, bond strength between concrete and OPBF reduced with age and increased with an 463 increase in the number of individual OPBF per tendon. Average percentage loss in bond strength at 464112 days for single OPBF was $41 \%$ while that for OPBF tendons was $25 \%$. Reductions in bond 
465 strength was due to interface degradation caused by the action of cement alkali on the surface of the 466 OPBF (Momoh and Osofero, 2019; Karade, 2010). Fibre surface degradation was however reduced 467 for the tendons because the combination of multiple fibres prevented contact between the entire 468 surface of each individual OPBF and the cementitious matrix.

469 Table 3.1: Results from pull-out experiment of OPBF from concrete

\begin{tabular}{|c|c|c|c|c|c|c|}
\hline $\begin{array}{l}\text { Sample } \\
\text { ID. }\end{array}$ & $\begin{array}{l}\text { Surface } \\
\text { area } \\
\text { of OPBF } \\
\text { Tendon } \\
\left(\mathrm{mm}^{2}\right)\end{array}$ & $\begin{array}{l}\text { Embedded } \\
\text { length } \\
(\mathrm{mm})\end{array}$ & $\begin{array}{l}\text { Average } \\
\text { Peak } \\
\text { Load P } \\
\text { (N) }\end{array}$ & $\begin{array}{l}\text { Bond } \\
\text { strength } \\
\sigma_{b}(\mathrm{MPa}) \\
\text { standard } \\
\text { deviation in } \\
\text { bracket }\end{array}$ & $\begin{array}{l}\text { Percentage } \\
\text { reduction in } \\
\text { bond strength } \\
\text { at } 56 \text { and } 112 \\
\text { days } \\
\text { (\%) }\end{array}$ & $\begin{array}{l}\text { Failure } \\
\text { Mode }\end{array}$ \\
\hline 1F-028 & 235.61 & 80 & 131.33 & $0.56(0.167)$ & - & pull-out \\
\hline $2 F-028$ & 530.00 & 80 & 306.6 & $0.58(0.042)$ & - & pull-out \\
\hline 3F-028 & 754.00 & 80 & 551.65 & $0.73(0.008)$ & - & pull-out \\
\hline 4F-028 & 770.00 & 80 & 654.80 & $0.85(0.1185)$ & - & pull-out \\
\hline $5 F-028$ & 900.00 & 80 & 822.00 & $0.91(0.002)$ & - & pull-out \\
\hline 6F-028 & 939.30 & 80 & 1092.00 & $1.16(0.193)$ & - & pull-out \\
\hline 1F-056 & 235.61 & 80 & 77.4 & $0.33(0.026)$ & 41.07 & pull-out \\
\hline 2F-056 & 530.00 & 80 & 217.10 & $0.41(0.089)$ & 29.31 & pull-out \\
\hline 3F-056 & 754.00 & 80 & 333.20 & $0.44(0.084)$ & 39.72 & pull-out \\
\hline 4F-056 & 770.00 & 80 & 540.40 & $0.70(0.026)$ & 17.65 & pull-out \\
\hline $5 F-056$ & 900.00 & 80 & 855.00 & $0.95(0.134)$ & -4.40 & pull-out \\
\hline 6F-056 & 939.30 & 80 & 843.00 & $0.90(0.026)$ & 22.41 & grip \\
\hline 1F-112 & 235.61 & 80 & 77.75 & $0.33(0.052)$ & 41.07 & pull-out \\
\hline 2F-112 & 530.00 & 80 & 217.04 & $0.41(0.134)$ & 29.31 & pull-out \\
\hline 3F-112 & 754.00 & 80 & 369.46 & $0.49(0.035)$ & 32.88 & pull-out \\
\hline 4F-112 & 770.00 & 80 & 477.40 & $0.62(0.129)$ & 27.06 & pull-out \\
\hline $5 F-112$ & 900.00 & 80 & 729.00 & $0.81(0.263)$ & 10.99 & grip \\
\hline 6F-112 & 939.30 & 80 & 770.23 & $0.82(0.208)$ & 29.31 & pull-out \\
\hline
\end{tabular}


471 The surface undulation of the tendons created by the helical winding of individual OPBF also resulted

472 in mechanical anchorage for increased bond resistance.

473 Observation of the mechanism of debonding of OPBF from the concrete matrix revealed that tendon

474 pull-out and tear were observed beyond 56 days. While single fibre pull-out was characterised by

475 gradual debonding and subsequent pulling out of fibres, OPBF tendon pull-out was characterised by

476 debonding, followed by mechanical interlocking, then a combination of damage of individual fibres

477 and mechanical interlocking, and finally fracture/tearing of individual OPBF making up the tendon.

478 This is reflected as a predominant slip-softening behaviour for single OPBF as the bond stress

479 decayed rapidly after the maximum value. On the other hand, slip-hardening was observed for most

480 OPBF tendons such that a residual bond strength was maintained beyond the maximum value (see

481 Figure 3.1). Damage to tendons was proportional to the number of individual OPBF making up the

482 tendon. Figure 3.2 illustrates the damage to OPBF tendons after a forceful complete pull-out from the

483 concrete matrix at 112 days. This mechanism of failure leads to increase in energy absorption of

484 OPBF-concrete composite, a phenomenon observed in a previous study (Momoh and Osofero, 2019)

485 for random inclusion of OPBF in the form of $50 \mathrm{~mm}$ discrete fibres in concrete. Pull-out of OPBF

486 tendons without corresponding damage to concrete also imply that the shear stress borne by concrete

487 matrix was low.

SEM images revealing the embrittlement of OPBF surface, at 112 days, by cement alkali of the concrete matrix are presented in Figure 3.3. Alkali embrittlement, with time, resulted in the formation of an organic layer between the OPBF and the matrix, thus causing reduced shear resistance at the interface of the two materials. Consequently, adhesion between OPBF and the surrounding matrix deteriorated and resulted in reductions in bond strength with age of samples reported in Table 3.1 as percentage reduction in bond strength. Notwithstanding, an increase in the number of individual OPBF per tendon resulted in increased mechanical interlock with the concrete matrix. Consequently, linear correlations were observed between tendon size and bond stress at 28, 56 and 112 days (see Figure 3.4).

497 The maximum values of bond strength obtained in the study of Ramakrishna and Priyadharshini 498 (2018) for coir in 1:3 cement-sand mortar are about $40 \%$ of OPBF-concrete bond strength at 28 days. 
500

501

502

503

504

505

506

507

508

509

510

511

512

513

514

515

516

517

518

519

520

521

522

523

524

525

526

527

528

$\mathrm{MPa})$ are still higher than the range reported for other types of fibres in literature: (0.17-0.46 MPa) for jute fibres in cement mortar at 7 days (Ferreira, et al., 2016), (0.36-0.38 MPa) for sisal fibre in cement mortar at 28 days (Silva, et al., 2011) and (0.4-0.5 MPa) for polypropylene fibres in cement mortar at 28 days (Singh, et al., 2004). Maximum bond strength obtained at 28 days from this study (with 80 $\mathrm{mm}$ embedded length) is $66 \%$ of bond strength reported in (Sakaray, et al., 2012) for bamboo strips (at an embedded length of $150 \mathrm{~mm}$ ) in grade-30 concrete. It should be noted that using a similar embedded length of OPBF tendons (i.e. beyond $80 \mathrm{~mm}$ ) would cause an increase in mechanical interlock due to the helical arrangement of the fibres constituting the tendon, and hence result in higher values of bond strength. In addition, bond strength of OPBF reported in this study is about $14 \%$ of the reported bond strength between concrete and reinforcing steel bars (at an embedded length of $150 \mathrm{~mm}$ ) in grade-30 concrete at 28 days (Sakaray, et al., 2012). With an increased embedded length of OPBF tendons, bond strength would be adequate for lightly loaded elements like lintel beams of low-cost farm houses. Furthermore, the comparison of bond strength of OPBF with the range for untreated bamboo (0.73-0.9 MPa) at an embedded length of $150 \mathrm{~mm}$ in grade-20 concrete (Kute and Wakchaure, 2013) and surface treated bamboo (0.14-1.4 MPa) at an embedded length of $100 \mathrm{~mm}$ in grade-20 concrete (Mali and Datta, 2019), show that surface-treated OPBF with similar embedded length and grade of concrete could produce superior bond results. On the other hand, it is also important to note that the reported studies investigated different species of bamboo with varying mechanical properties, hence, an in-depth study on bond behaviour of OPBF from different oil palm trees and in various grades of concrete as well as at varying embedded lengths is also necessary.

Lack of bond-strength results beyond 28 days makes the comparison between values obtained from literature, with that for OPBF in concrete, difficult. However, a comparison between the 112 days bond strength of single OPBF and tendons with the 28 days bond strengths reported for other vegetable fibres, indicate that the surface of OPBF has good resistance to surface degradation. This preserved the bond strength with time and implies a superior performance for OPBF as reinforcement for cementitious matrices. Oil palm fibres have good resistance to deterioration due to the high content of silica bodies on the surface (Omar, et al., 2014).

The resulting finite element simulation (Figure 2.5) also shows that stress in the concrete is minimum thereby corroborating the pull-out of OPBF tendons without damage to surrounding concrete as 
observed in the experiment. Therefore, the cohesive surface bond model is adequate for simulating bond between concrete and the OPBF-tendons. Figure 3.5 shows the accuracy of the numerical model as validated with the experimental results at 28 days. Numerical modelling of time rate of degradation of concrete/OPBF interface should be investigated in order to accurately predict bond strength in the long term. The use of finite element simulation would enable parametric studies that would otherwise be difficult and time-consuming with physical experiments.

From the correlation between bond strength and number of OPBF per tendon shown in Figure 3.4, linear relationships were derived and are shown in Eqns 3.1-3.3.

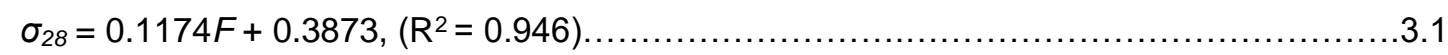

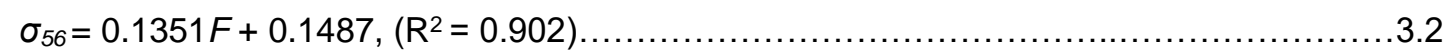

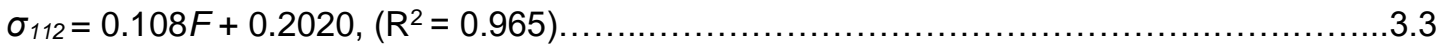

where $\sigma_{28}, \sigma_{56}$ and $\sigma_{112}$ are the bond strengths at 28,56 and 112 days, respectively, and $(1 \leq F \leq 6)$ is the number of OPBF in the tendon. The $R^{2}$ values of $0.946,0.902$ and 0.965 of Eqns 3.1-3.3 for bond strengths 28,56 and 112 days, respectively, show a strong correlation between bond stress and number of individual OPBF making up a tendon.

An obvious superiority of conventional steel reinforcement over plant fibres is the high shear resistance of the surface of the reinforcement. While steel is homogeneous and is not embrittled by cement alkali, plant fibres surfaces undergo alkali-induced degradation, thereby weakening and resulting in loss adhesion with surrounding concrete. Consequently, bond strength reduces with time as the degrading action at the matrix-fibre interface progresses. It is reported that time-related degradation of vegetable fibres surface, in cement alkali, can be minimised by pre-treating fibres with alkali solution (Machaka, et al., 2014) or silane solution (Blankenhorn, et al., 2001). Although these treatments are currently being investigated for their effectiveness in enhancing bond behaviour of OPBF tendons in concrete matrix, they have been proven for discrete plant fibres meant for random distribution in cementitious matrices. For practicality, factors such as cost of treatment, recovery of chemicals from effluents or environmental impact of effluent disposal should be measured against the target improvement desired for the composite. Possible ways of improving shear resistance of the surface of natural reinforcements include pre-coating the reinforcement surfaces with structural adhesives (Agarwal et al., 2014) and the use of shear connectors (in form of hose clamps) to 
558

559

560

561

562

563

564

565

566

567

568

569

570

571

572

573

574

575

576

577

578

579

580

581

582

583

584

585

586

\section{2}

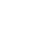

maximise mechanical interlocking and shear transfer between the reinforcement and host matrix (Muhtar et al., 2019). A combination of both enhancement strategies could result in a hybrid reinforcement material and is an area for further research. Combining OPBF into tendons using hose clamps would mobilise the full tension capacity of the tendons in the matrix. Hence subsequent studies by the authors on the use of OPBF as structural reinforcement analogous to bamboo reinforcement would consider the use of hose clamps as shear connectors.

A comparison of bond strength between concrete and structural materials such as steel and bamboo is presented in Table 3.2. Bond strength between OPBF and concrete at 28 days is about $40 \%$ of that of thermo-mechanically treated (TMT) steel and $65 \%$ of that of mild steel. At 112 days, it reduces to about $29 \%$ of TMT steel and $46 \%$ of that of mild steel. Though bamboo is the most-recommended natural reinforcement for concrete, it is difficult to compare its long-term bond performance with OPBF's as most studies are limited to 28 days values. However, the 112 days bond strength value for OPBF tendons competes favourably with the 28 days bond strength of untreated bamboo in similar matrix. Long-term performance of OPBF in concrete is currently a grey area of research. Therefore, further investigation is required in this direction. For practical application of OPBF tendons for reinforcement in concrete, a study of the time-rate of interface degradation needs to be carried out to assess long term performance of the composite. Furthermore, the correlation between tendon size (of above 6 OPBF per tendon) and bond strength requires further study. Although it is obvious that the combination of multiple fibres in form of tendons prevents contact between the entire surfaces of individual OPBF and the cementitious matrix, the limit at which this linear relationship (Figure 3.4) ceases to exist will inform OPBF- reinforced concrete design procedure and recommendations. 政

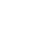
.

(1)


Table 3.2: Comparison of bond strength of Steel, OPBF and Bamboo in concrete

\begin{tabular}{|c|c|c|c|c|c|}
\hline Material & $\begin{array}{l}28 \text { days } \\
\text { bond } \\
\text { strength } \\
\text { (MPa) }\end{array}$ & $\begin{array}{c}\text { Embedded } \\
\text { length } \\
(\mathrm{mm})\end{array}$ & $\begin{array}{l}\text { Compressive } \\
\text { strength of } \\
\text { concrete } \\
\text { (MPa) }\end{array}$ & $\begin{array}{l}\text { Percentage } \\
\text { bond } \\
\text { strength of } \\
\text { TMT steel } \\
(\%)\end{array}$ & Reference \\
\hline TMT* steel $^{*}$ & 2.87 & 150 & 20 & -- & $\begin{array}{l}\text { Kute and Wakchaure, } \\
2013\end{array}$ \\
\hline Mild steel & 1.79 & 150 & 20 & 62.4 & $\begin{array}{c}\text { Kute and Wakchaure } \\
2013\end{array}$ \\
\hline $\begin{array}{l}\text { OPBF } \\
(6 \mathrm{~F}-028)\end{array}$ & 1.16 & 80 & 30 & 40.4 & This study \\
\hline $\begin{array}{l}\text { Bamboo } \\
\text { (D. giganteus) } \\
\text { with node }\end{array}$ & 1.20 & 100 & 19 & 41.8 & Ghavami 1995 \\
\hline $\begin{array}{l}\text { Bamboo } \\
\text { (D. giganteus) } \\
\text { without node }\end{array}$ & 0.52 & 100 & 19 & 18.1 & Ghavami 1995 \\
\hline $\begin{array}{l}\text { Bamboo } \\
\text { (D. asper) }\end{array}$ & 1.00 & 200 & 30 & 34.8 & Muhtar et al. 2019 \\
\hline $\begin{array}{l}\text { Bamboo } \\
\text { (D. strictus) }\end{array}$ & 0.73 & 150 & 20 & 25.4 & $\begin{array}{l}\text { Kute and Wakchaure, } \\
2013\end{array}$ \\
\hline $\begin{array}{l}\text { Bamboo } \\
\text { (G. apus) }\end{array}$ & 0.41 & 150 & 12 & 14.3 & $\begin{array}{l}\text { Nindyawati and } \\
\text { Umniati } 2016\end{array}$ \\
\hline $\begin{array}{l}\text { Bamboo } \\
\text { (M. bambusoides) }\end{array}$ & 0.13 & 100 & 20 & 4.4 & Agarwal et al. 2014 \\
\hline
\end{tabular}

${ }^{*} \mathrm{TMT}=$ thermo-mechanically treated

588

$589 \quad 4 . \quad$ Conclusions

590 This study presented results of an experimental investigation into the bond behaviour of OPBF, as

591 single fibres and in combined form as tendons in normal strength concrete at 28,56 and 112 days. A

592 finite element modelling of bond behaviour between the two materials was also carried out.

593 Consequently, the following conclusions have been made:

594 - Maximum bond strengths of 1.16 MPa, $0.95 \mathrm{MPa}$ and $0.82 \mathrm{MPa}$ were achieved at 28, 56 and

$595 \quad 112$ days respectively;

596 - Average percentage reduction of bond strength at 112 days is $28.4 \%$. This is due to the

597 degradation of OPBF surface in the concrete environment with time;

598 - Bond strength increased with an increase in the number of individual OPBF making up a

$599 \quad$ tendon;

600 - Pre-treatment of OPBF is recommended for cement matrices in order to prevent surface

601 degradation of the fibres by cement alkali; 
- Interface bond stress between OPBF and concrete can be modelled using cohesive surface approach in ABAQUS.

604 Further investigations are required to understand the long-term bond behaviour of OPBF tendons and

605 also OPBF tendons consisting of more than 6 fibres in concrete. Evaluation of improvement methods

606 for the shear resistance between the tendons and concrete is also recommended. The use of OPBF

607 for construction aside being eco-friendly could reduce material importation for developing countries

608 with huge housing deficits.

609 Acknowledgements

610 The authors would like to thank the Petroleum Technology Development Fund (PTDF) of Nigeria for

611 sponsoring this research.

\section{Conflict of Interest}

613 None.

614

615

616

617

618

619

620

621

622

623

624

625

626

627

628

629 
ABAQUS (2019). Contact formulations for contact pairs in Abaqus/Explicit. See https://abaqusdocs.mit.edu/2017/English/SIMACAEITNRefMap/simaitn-c-expcontactpairform.htm\#simaitn-cexpcontactpairform-sliding , Massachusets Institute of Technology, USA. (accessed 29/10/2019).

ACI (American Concrete Institute) (2003) ACl 408R-03: Bond and development of straight reinforcing bars in tension. American Concrete Institute, Farmington Hills, MI, USA.

637 Agarwal A, Nanda B, and Maity D (2014) Experimental investigation on chemically treated bamboo

638 reinforced concrete beams and columns. Construction and Building Materials 71: 610-617.

639 Agopyan A, Savastano HJ, John VM, and Cincotto M A (2005) Developments on vegetable fibre640 cement based materials in Sao Paulo, Brazil: an overview. Cement and Concrete Composites 27(5): $641 \quad 527-536$.

642 Ali A, Lo Conte A, Biffi CA, and Tuissi A (2019) Cohesive surface model for delamination and dynamic 643 behavior of hybrid composite with SMA-GFRP interface. International Journal of Lightweight Materials 644 and Manufacture 2: 146-155.

645 Alizadeh V (2019) Finite element analysis of controlled low strength materials. Frontiers of Structural 646 and Civil Engineering 13(5), 1-8.

647 ASTM (2016) D4442-16: Standard test methods for direct moisture content measurement of wood 648 and wood-based materials. ASTM International, West Conshohocken, PA, USA.

649 Ardanuy M, Claramunt $\mathrm{J}$ and Filho RDT (2015) Cellulosic fiber reinforced cement-based composites: 650 A review of recent research. Construction and Building Materials 79: 115-128.

ASTM (2014) C136/C136M-14: Standard test method for sieve analysis of fine and coarse aggregates. ASTM International, West Conshohocken, PA, USA.

653

Bah EM, Faye I and Geh ZF (2018) The Housing Sector in Africa: Setting the Scene. In: Housing Market Dynamics in Africa. Palgrave Macmillan, London. micromechanical model for intergranular degradation and failure in polycrystalline materials. Computer Methods in Applied Mechanics and Engineering, 265: 36-62.

Blankenhorn PR, Blankenhorn BD, Silsbee MR, and DiCola M (2001) Effects of fiber surface treatments on mechanical properties of wood fiber-cement composites. Cement and Concrete Research 31: 1049-1055.

Camanho P P and Dávila CG (2002) Mixed-mode decohesion finite elements for the simulation of delamination in composite materials. See https://ntrs.nasa.gov/archive/nasa/casi.ntrs.nasa.gov/20020053651.pdf , NASA, USA. (accessed 29/10/2019) 
671 Claramunt J, Lucía F-CJ, Ventura H and Ardanuy M (2016) Natural fiber nonwoven reinforced cement 672 composites as sustainable. Construction and Building Materials 115: 230-239.

673 Fantilli AP and Vallini P (2007) A cohesive interface model for the pullout of inclined steel fibers in 674 cementitious matrixes. Journal of Advanced Concrete Technology 5(2): 247-258.

675 Farzad L, Das S and Zhou C (2014) Separation force analysis and prediction based on cohesive 676 element model for constrained-surface Stereolithography processes. Computer-Aided Design 69: $677 \quad 134-142$.

678 Ferreira SR, Martinelli E, Pepe M, de Andrade Silva F and Filho RDT (2016) Inverse identification of 679 the bond behavior for jute fibers in cementitious matrix. Composites Part B: Engineering 95: 440-452.

680 Ferreira SR, Pepe M, Martinelli E, de Andrade Silva F and Filho RDT (2018) Influence of natural 681 fibers characteristics on the interface mechanics with cement based matrices. Composites Part B: 682 Engineering 140: 183-196.

683 Ganesan N, Indira PV and Himasree PR (2018) Bamboo reinforced concrete wall panels under one 684 way in-plane action. Environment, Development and Sustainability 1-14.

685 Ghavami K (1995) Ultimate load behaviour of bamboo-reinforced lightweight concrete beams.

686 Cement and Concrete Composites 17: 281-288.

687 Hadi MN (2008) Bond of High Strength Concrete with High Strength Reinforcing Steel. The Open Civil 688 Engineering Journal 2: 143-147.

689 Hamid $B$ and Abdelmadjid $H(2016)$ Influence of treatments on the date palm fiber and cement matrix 690 behavior: tensile and pull-out tests. American Journal of Civil Engineering and Architecture 4(6): 211 691215.

692 Issa CA and Masri O (2015) Numerical simulation of the bond behavior between concrete and steel 693 reinforcing bars in specialty concrete. International Journal of Civil and Environmental Engineering 694 9(6): 767-774.

695 Jendele L and Cervenka J (2006) Finite element modelling of reinforcement with bond. Computers \& 696 Structures 84: 1780-1791.

697 Karade SR (2010) Cement-bonded composites from lignocellulosic wastes. Construction and Building 698 Materials 24(8): 1323-1330.

699 Khalfallah S and Ouchenane M (2007) A numerical simulation of bond for pull-out tests: the direct 700 problem. Asian Journal of Civil Engineering (Building and Housing) 8(5): 491-505.

701 Khatun R, Reza MIH, Moniruzzaman M and Yaakob Z (2017) Sustainable oil palm industry: The 702 possibilities. Renewable and Sustainable Energy Reviews 76: 608-619.

703 Kute SY and Wakchaure MR (2013) Performance evaluation for enhancement of some of the 704 engineering properties of bamboo as reinforcement in concrete. Journal of The Institution of 705 Engineers (India): Series A 94(4): 235-242.

706 Machaka M, Basha H, Chakra HA and Elkordi A (2014) Alkali treatment of fan palm natural fibers for 707 use in fiber reinforced concrete. European Scientific Journal 10(12): 186-195.

708 Mali PR. and Datta D (2018) Experimental evaluation of bamboo reinforced concrete slab panels.

709 Construction and Building Materials 188: 1092-1100. 
710 Mali PR and Datta D (2019) Experimental study on improving bamboo concrete bond strength.

711 Advances in concrete construction 7(3): 191-201.

712 Momoh EO and Dahunsi BIO (2017) Suitability of oil-palm-broom-fibres as reinforcement for lateritebased roof tiles. International Journal of Software \& Hardware Research in Engineering

714 5(4): 27-35.

715 Momoh EO and Osofero Al (2019). Behaviour of oil palm broom fibres (OPBF) reinforced concrete.

716 Construction and Building Materials, 221: 745-761.

717 Momoh EO and Osofero Al (2020). Recent developments in the application of oil palm fibres in

718 cement composites. Frontiers of Structural and Civil Engineering. https://doi.org/10.1007/s11709-019-

719 0576-9.

720 Momoh EO, Osofero Al, Martinez-felipe A and Hamza F (2020) Physico-mechanical behaviour of Oil

721 Palm Broom Fibres (OPBF) as eco-friendly building material. Journal of Building Engineering 30:

722101208.

Morrissey FE, Coutts RSP and Grossman PUA (1985) Bond between cellulose fibres and cement. International Journal of Cement Composites and Lightweight Concrete 7(2): 73-80.

Muhtar M, Dewi SM and Munawir A (2019) Enhancing bamboo reinforcement using a hose-clamp to increase bond-stress and slip resistance. Journal of Building Engineering 26: 100896.

Naik DL, Sharma A, Chada RR, Kiran R and Sirotiak T (2019) Modified pullout test for indirect characterization of natural fiber and cementitious matrix interface properties. Construction and Building Materials 208: 381-393.

Nindyawati N and Umniati BS (2016) Bond strength of bamboo reinforcement in light weight concrete. Journal of Civil Engineering and Architecture 10: 417-420.

Omar FN, Mohammed MAP and Baharuddin AS (2014) Effect of silica bodies on the mechanical behaviour of oil palm empty fruit bunch fibres. BioResources 9(4): 7041-7058.

Onuaguluchi $O$ and Banthia N (2016) Plant-based natural fibre reinforced concrete composites: a review. Cement and Concrete Composites, 68: 96-108.

Osofero Al, Corradi M and Borri A (2015) Experimental study of bond strength between titanium bar and lime-based mortar. Journal of Materials in Civil Engineering 27(6): 1-10.

Pacheco-Torgal $\mathrm{F}$ and Jalali S (2010) Cementitious building materials reinforced with vegetable

740 https://doi.org/10.1016/j.conbuildmat.2010.07.024

741 Pacheco-Torgal F and Jalali S (2011) Natural fiber reinforced concrete. In: Fibrous and Composite 742 Materials for civil Engineering Applications (Ed: R. Fangueiro). Woodhead Publishing. Pp. 154-167. 743 https://doi.org/10.1533/9780857095583.2.154

744 Page J, Khadraoui F, Boutouil M and Gomina M (2017) Multi-physical properties of a structural concrete incorporating short flax fibers. Construction and Building Materials, 140: 344-353.

746 Pereira H, Cunha V and Sena-Cruz J (2015) Numerical simulation of galvanized rebars pullout. 747 Frattura ed Integrità Strutturale 31: 54-66. 
Ramakrishna G and Sundararajan T (2005) Impact strength of a few natural fibre reinforced cement mortar slabs: a comparative study. Cement and Concrete Composites, 27(5): 547-553.

Ramamurthi M, Lee J-S, Yang S-H and Kim Y-S (2013) Delamination characterization of bonded interface in polymer coated steel using surface based cohesive model. International Journal of Precision Engineering and Manufacturing 14(10): 1755-1765.

Sakaray H, Togati NVVK and Reddy IVR (2012) Investigation on properties of bamboo as reinforcing material in concrete. International Journal of Engineering Research and Applications (IJERA) 2(1): 77-83.

Savastano Jr H and Agopyan V (1999) Transition zone studies of vegetable fibre-cement paste composites. Cement and Concrete Composites 21: 49-57.

Seixas MA, Ripper LA and Ghavami K (2014) Deployable bamboo structure for sustainable architecture. In Proceedings of the 15th International Conference on Non-Conventional Materials and Technologies, Pirassununga, Brazil, pp. 23-25.

Serpieri R, Alfano G and Sacco E (2015) A mixed-mode cohesive-zone model accounting for finite dilation and asperity degradation. International Journal of Solids and Structures 67-68: 102-115.

Silva FA, Mobasher B, Soranakom C and Filho RDT (2011) Effect of fiber shape and morphology on interfacial bond and cracking behaviors of sisal fiber cement based composites. Cement \& Concrete Composites 33: 814-823.

Singh P and Scanlon A (2013) Concrete in Residential Construction. Housing Research Center, Pennsylvania, USA.

Singh S, Shukla A and Brown R (2004) Pullout behavior of polypropylene fibers from cementitious matrix. Cement and Concrete Research 34: 1919-1925.

Soulioti DV, Barkoula N-M, Koutsianopoulos F, Charalambakis N and Matikas TE (2013) The effect of fibre chemical treatment on the steel fibre/cementitious matrix interface. Construction and Building Materials 40: 77-83.

Sun CT and Jin Z-H (2012) Cohesive Zone Model. In Fracture Mechanics. Elsevier, ISBN: 978-0-12385001-0 pp. 227-246.

Wan KT and Parris J (2016) Investigation of natural fibre reinforced cementitious composite for structural retrofitting of building structures. In International Association for Bridge and Structural Engineering (IABSE) Symposium Report, Stockholm, Sweden, 106(7), pp. 623-629.

Wei J and Meyer C (2014) Improving degradation resistance of sisal fiber in concrete through fiber surface treatment. Applied Surface Science 289: 511-523.

Wei J and Meyer C (2015) Degradation mechanisms of natural fiber in the matrix of cement composites. Cement and Concrete Research 73: 1-16.

Zenon A and Pilakoutas K (2004) Bond behavior of fiber reinforced polymer bars under direct pullout conditions. Journal of Composites for Construction 8(2): 173-181. 

Eco-friendly Construction

Momoh, Emmanuel Owoichoechi ${ }^{1}$ Osofero, Adelaja Israel ${ }^{2}$ Menshykov, Oleksandr ${ }^{3}$ School of Engineering, University of Aberdeen, King's College, Aberdeen, AB24 3UE, United Kingdom ${ }^{1,2,3}$

r01eom18@abdn.ac.uk1,aiosofero@abdn.ac.uk²,o.menshykov@abdn.ac.uk³

Figures

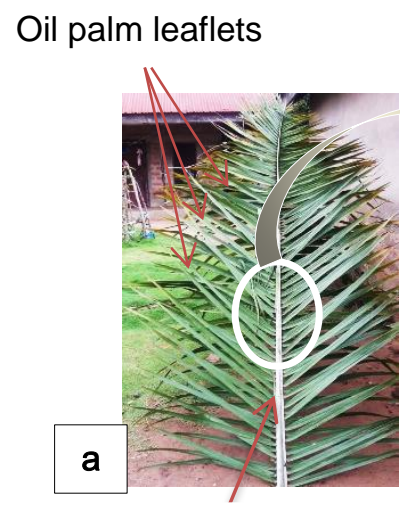

Petiole (frond)

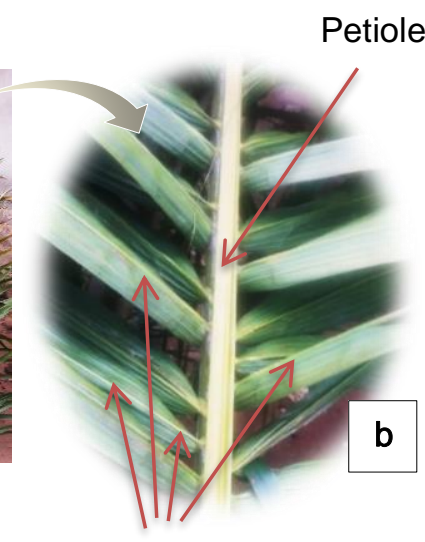

Ribs of oil palm leaflets

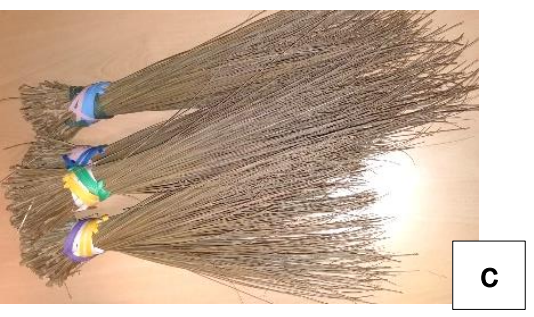

Brooms

Figure 1.1: Illustration of OPBF: (a) oil palm leaf; (b) magnified image of oil palm leaf; (c) OPBF tied into broom units (Momoh and Osofero 2020)

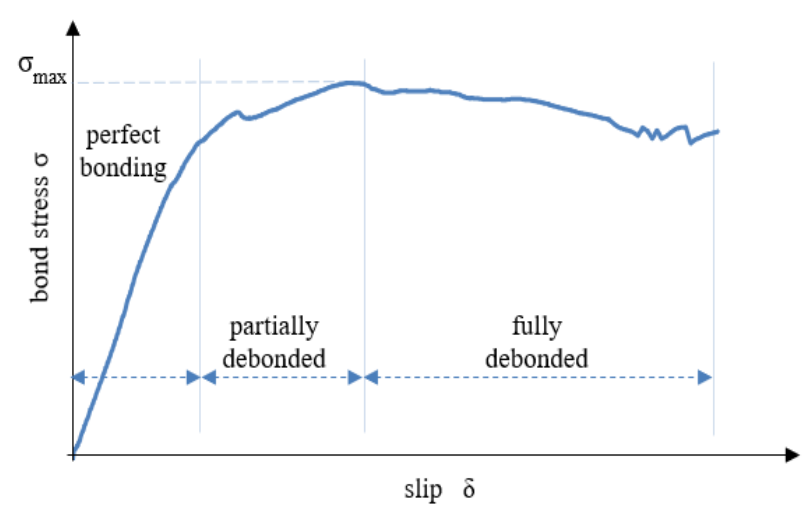

Figure 1.2: Typical stress-displacement curve of pull-out of a single OPBF from concrete 


\section{$\mathbf{a}$}

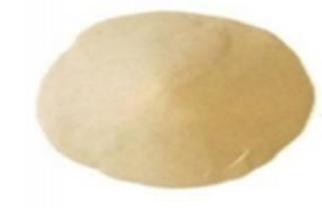

Medium sand

$0.07-3.4 \mathrm{~mm}$

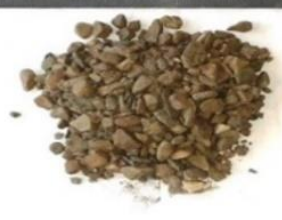

Fine gravel $0.1-10 \mathrm{~mm}$

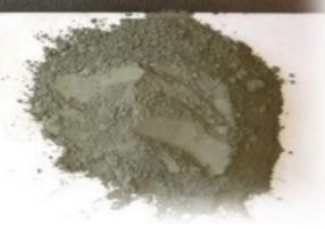

General purpose cement
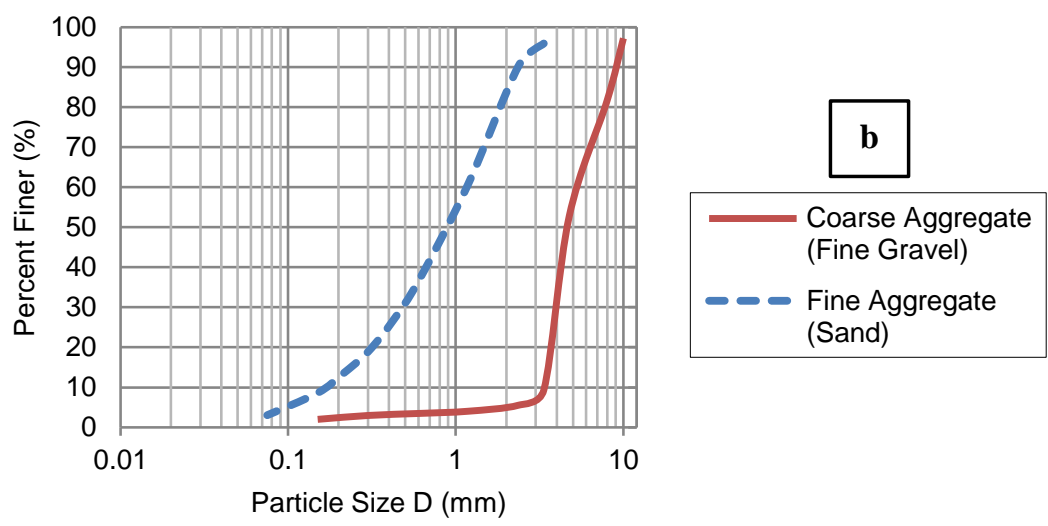

Figure 2.1: (a) Constituents of concrete; (b) Grading curves of fine and coarse aggregates
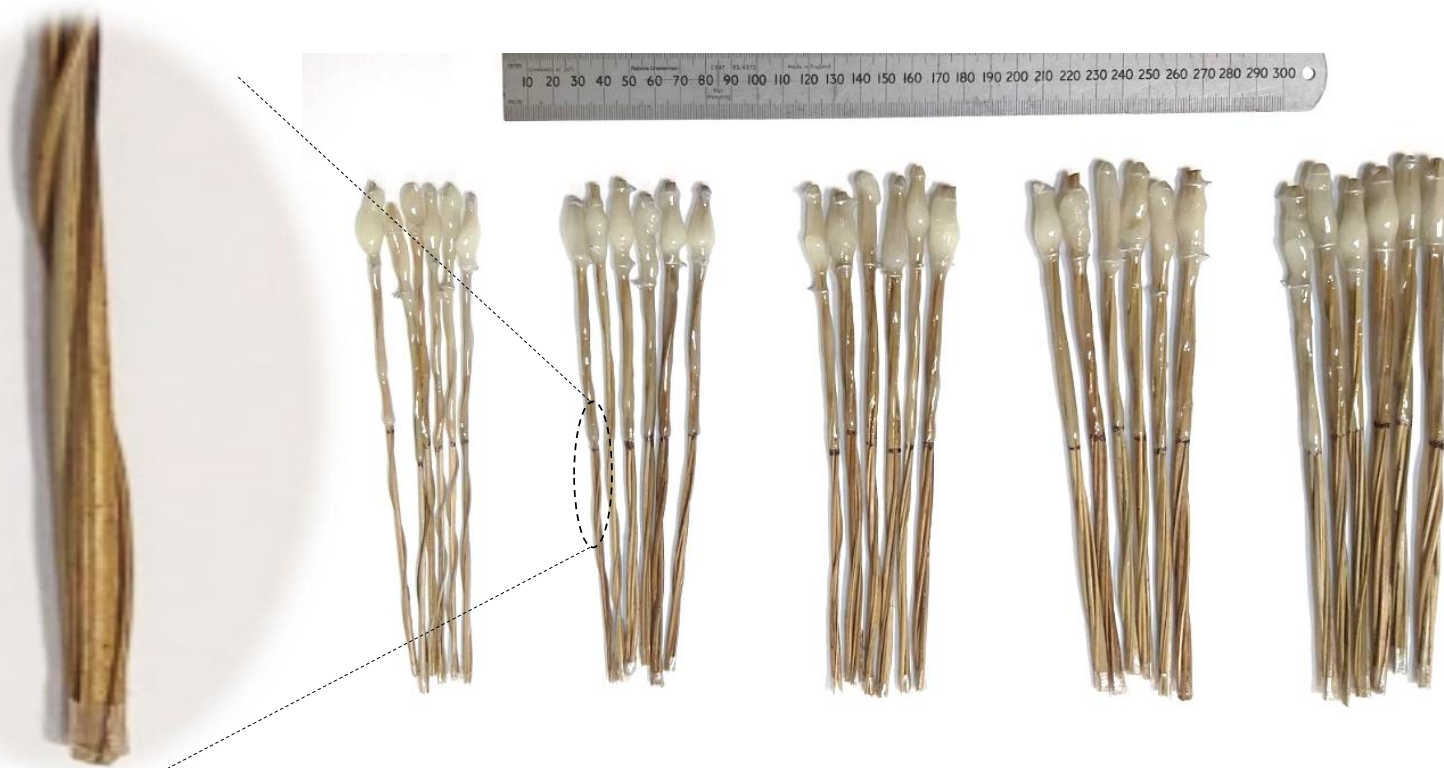

Figure 2.2: Illustration of OPBF tendons consisting of (from left to right) 2, 3, 4, 5 and 6 fibres per tendon respectively 

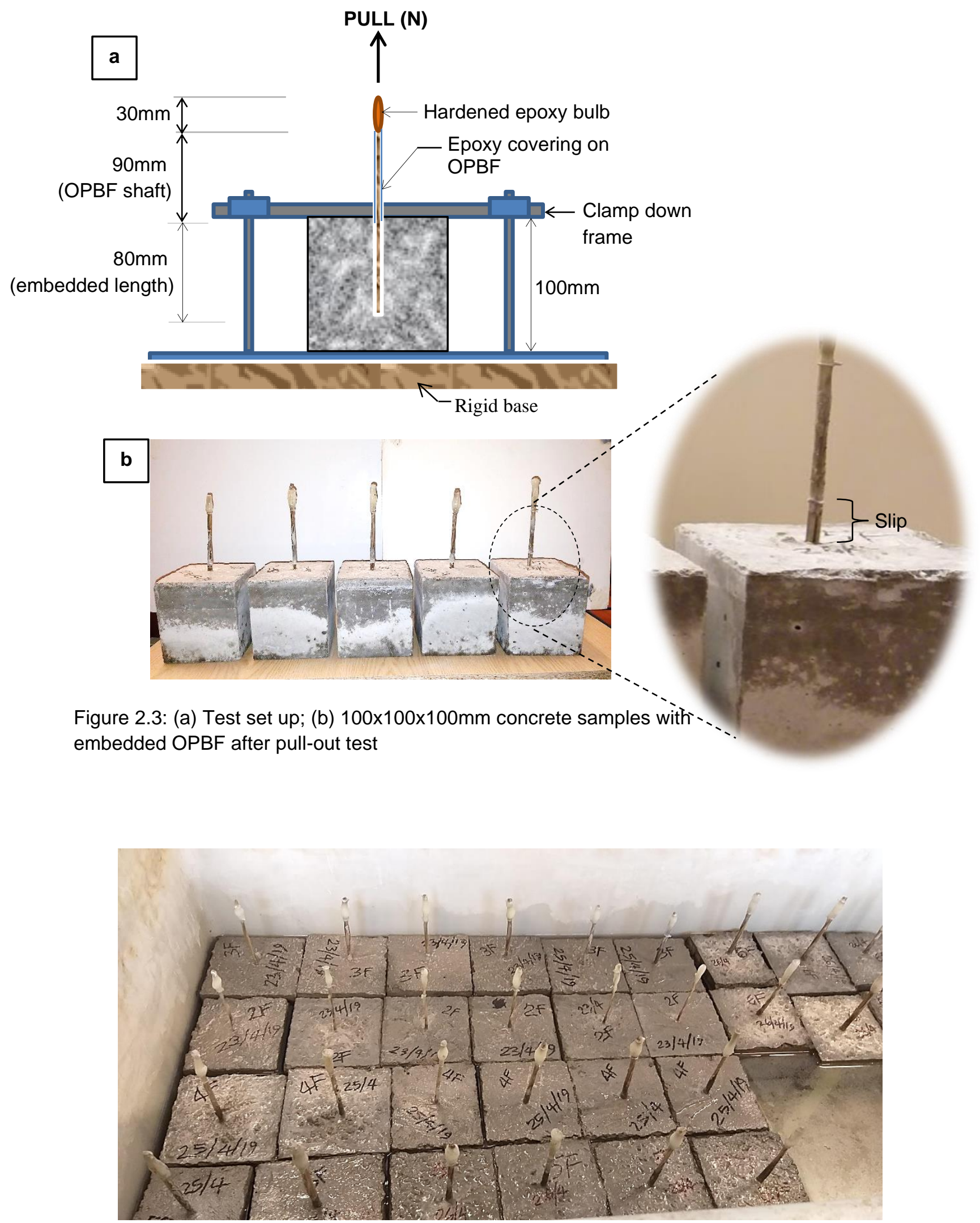

Figure 2.4: Curing of samples 


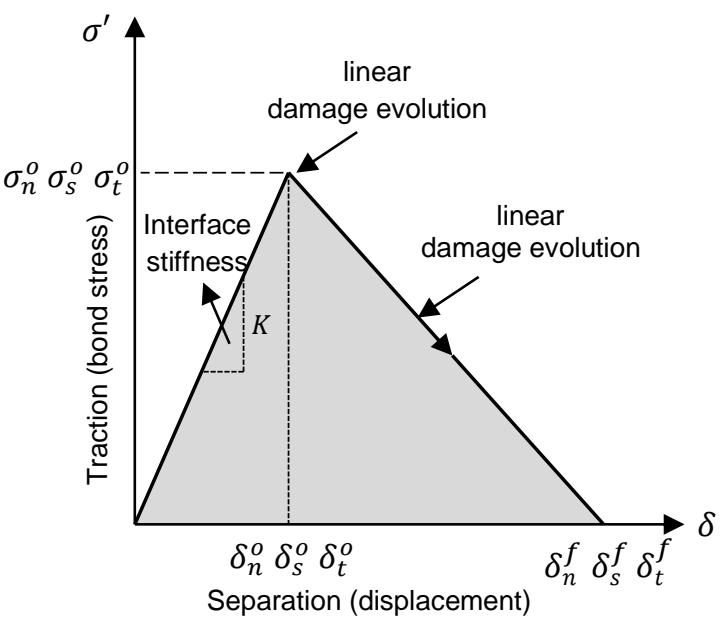

Figure 2.5: Traction-separation response

813

814

815

816

817

818

819

820

821

822

823

824

825 

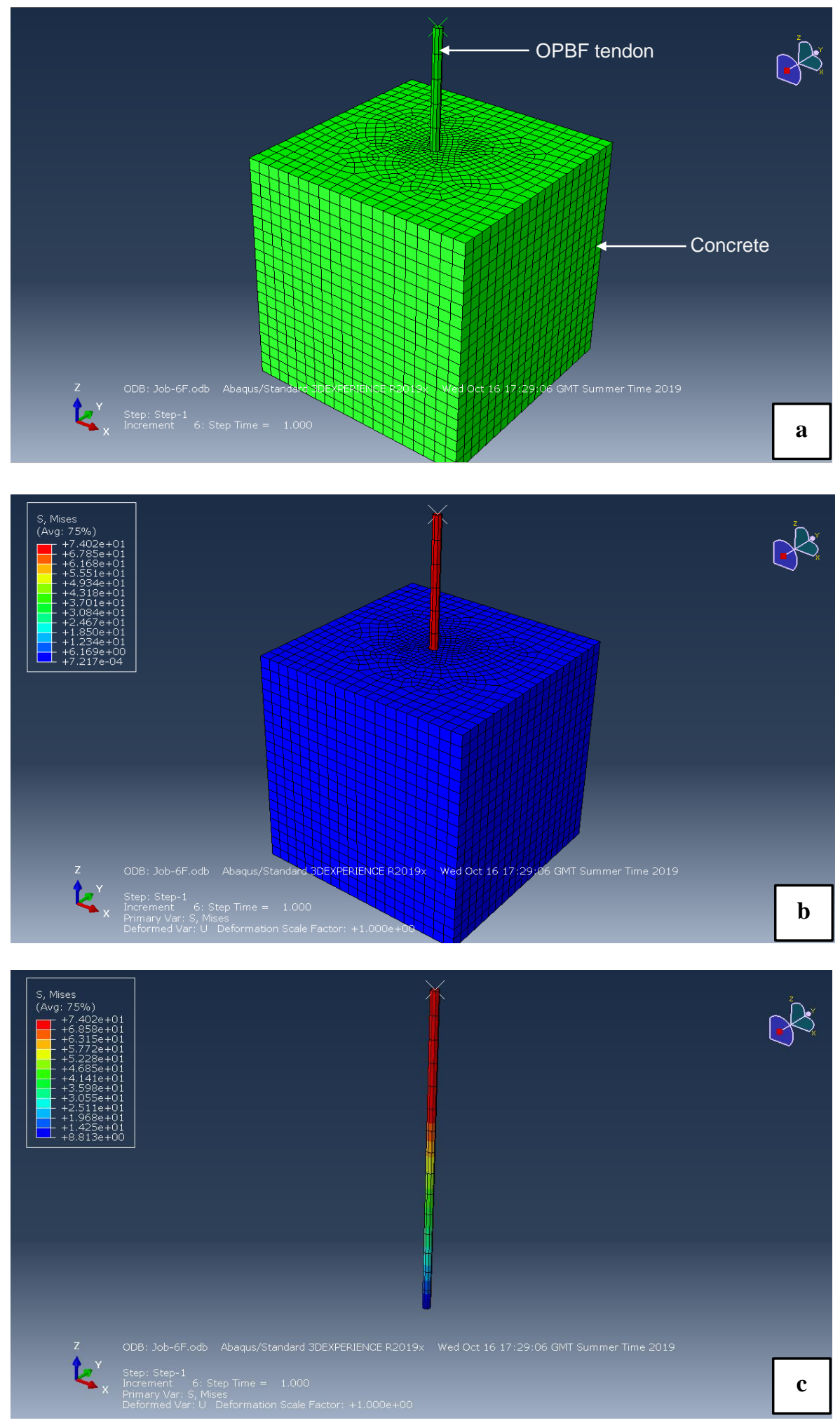

Figure 2.6: (a) Meshing arrangement of model; (b) Stress distribution at the end of simulation; (c) Stress distribution on a model of OPBF tendon 

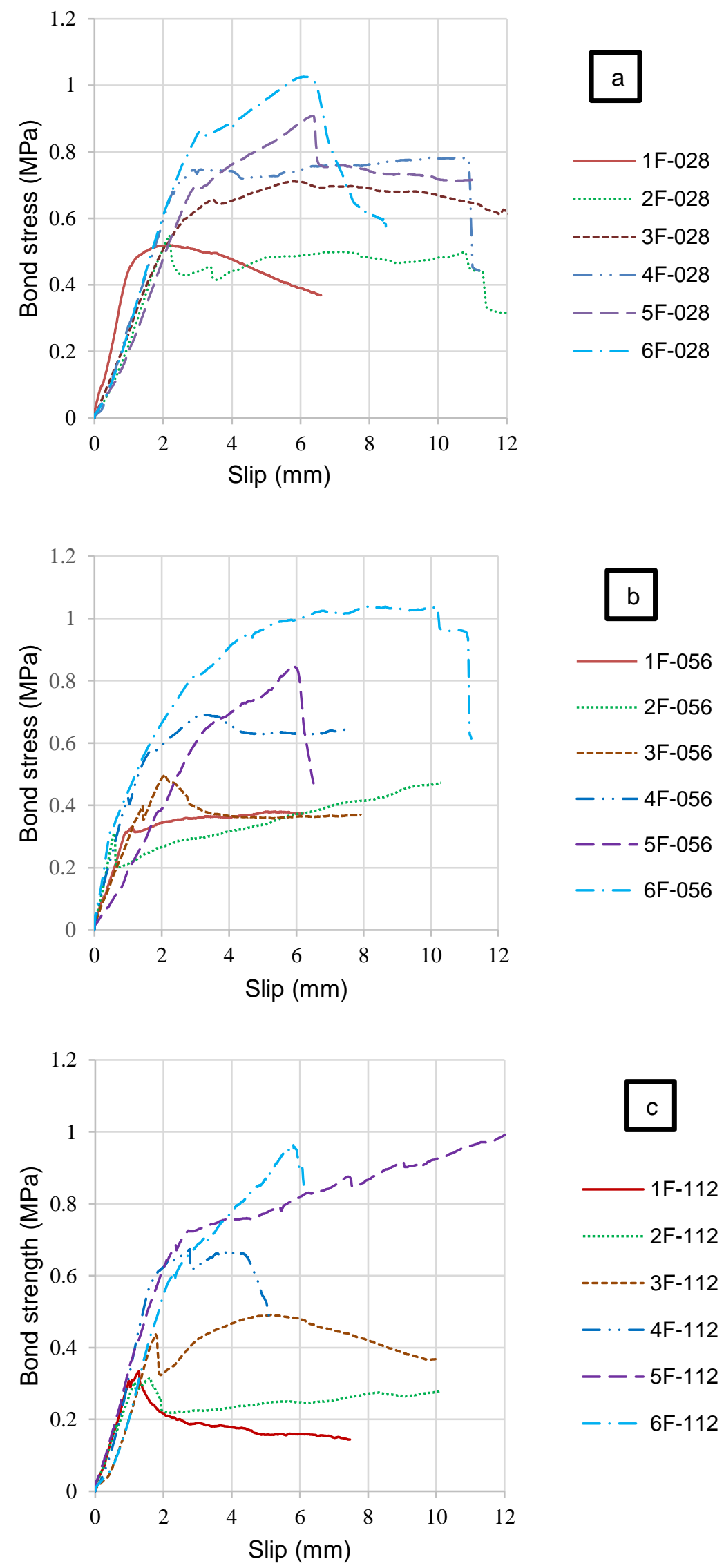

Figure 3.1: Bond stress curves at; (a) 28, (b) 56 and (c) 112 days 

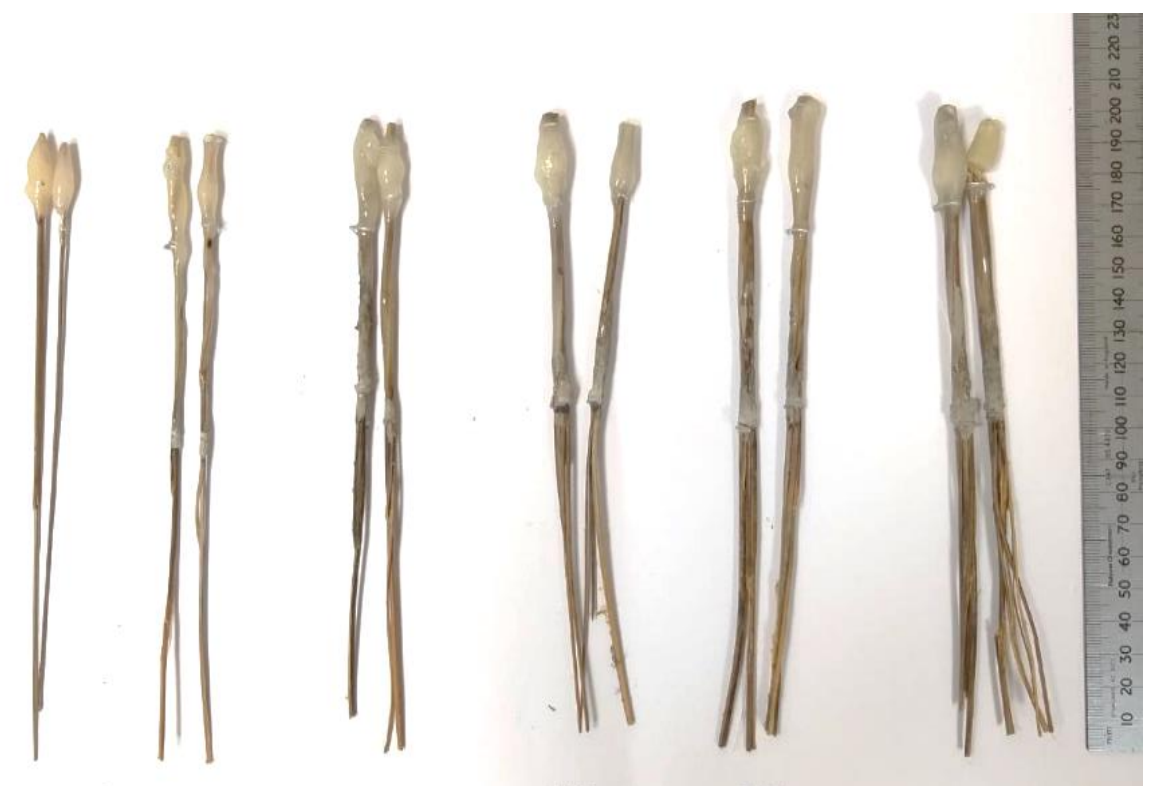

IF

$2 F$

3F

$4 F$

$5 F$

6F

Figure 3.2: Illustration of damage to OPBF after complete pull-out at 112 days 

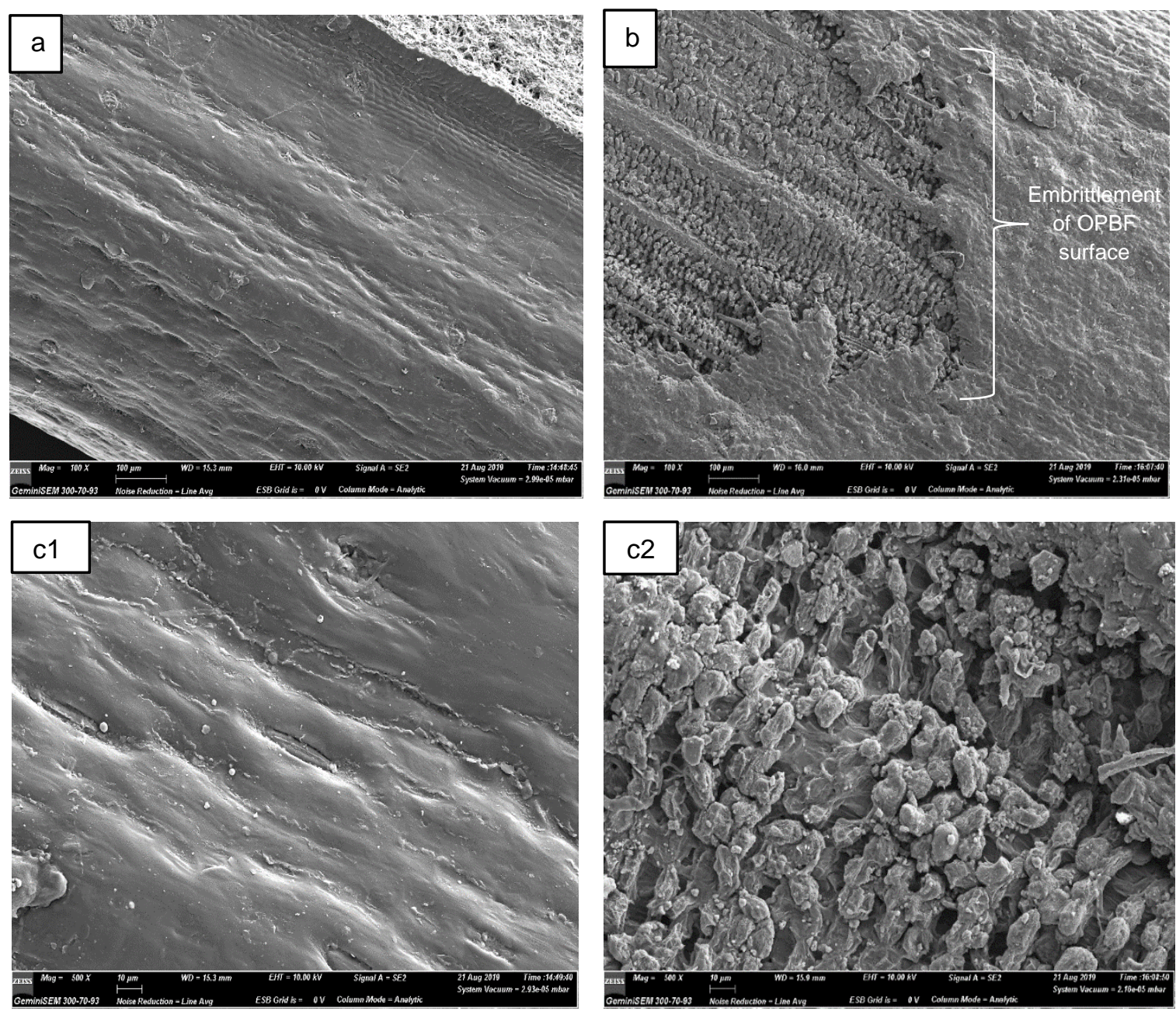

Fig 3.3: Scanning Electron Microscopy of OPBF surfaces:

(a) Before inserting in concrete $\times 100$;

(b) 112 days of inserting in concrete $\times 100$;

(c1) Unembrittled surface of OPBF $\times 500$;

(c2) Embrittled surface of OPBF $\times 500$. 


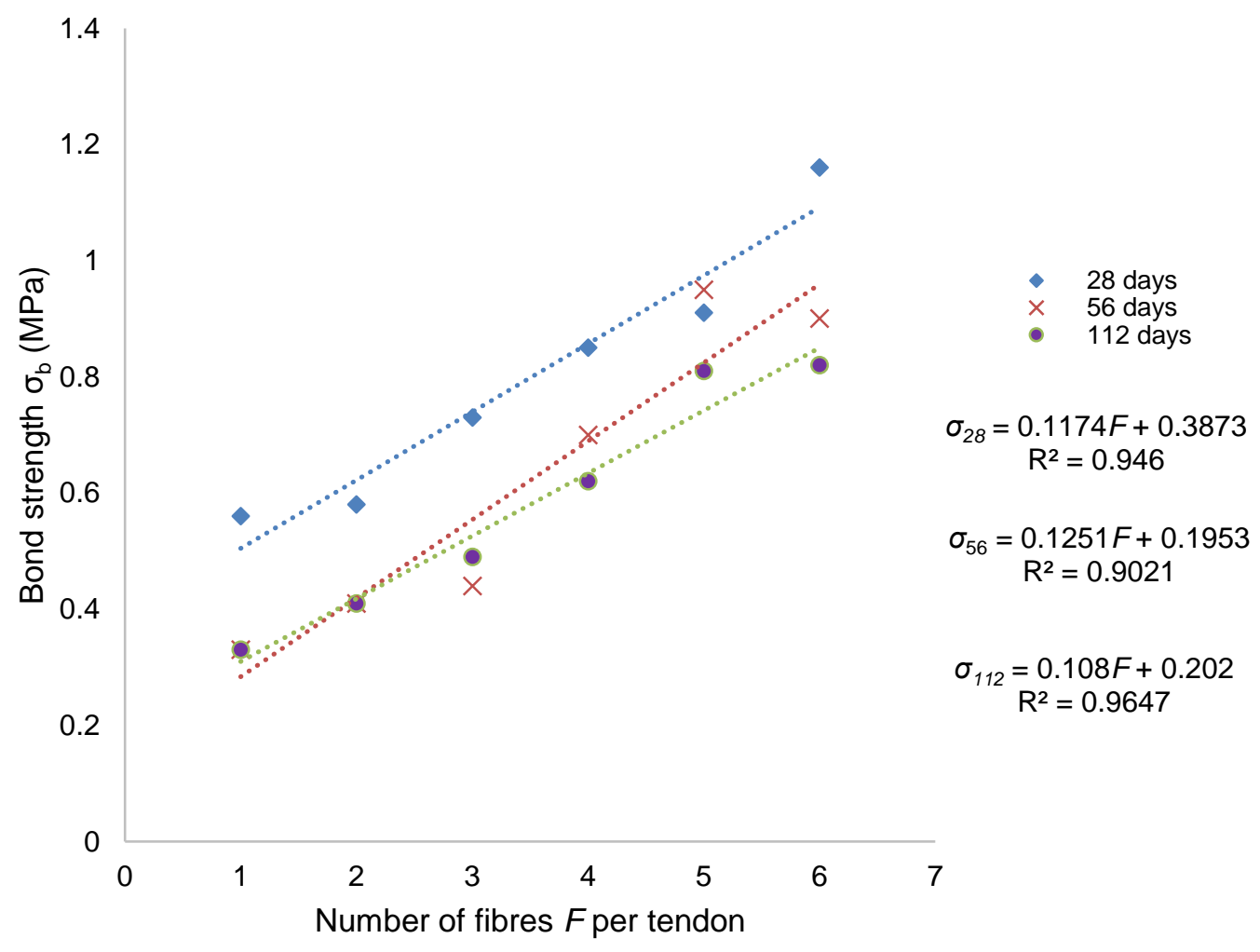

Figure 3.4: Linear models of bond stress between concrete and OPBF at 28, 56 and 112 days

839

840

841 

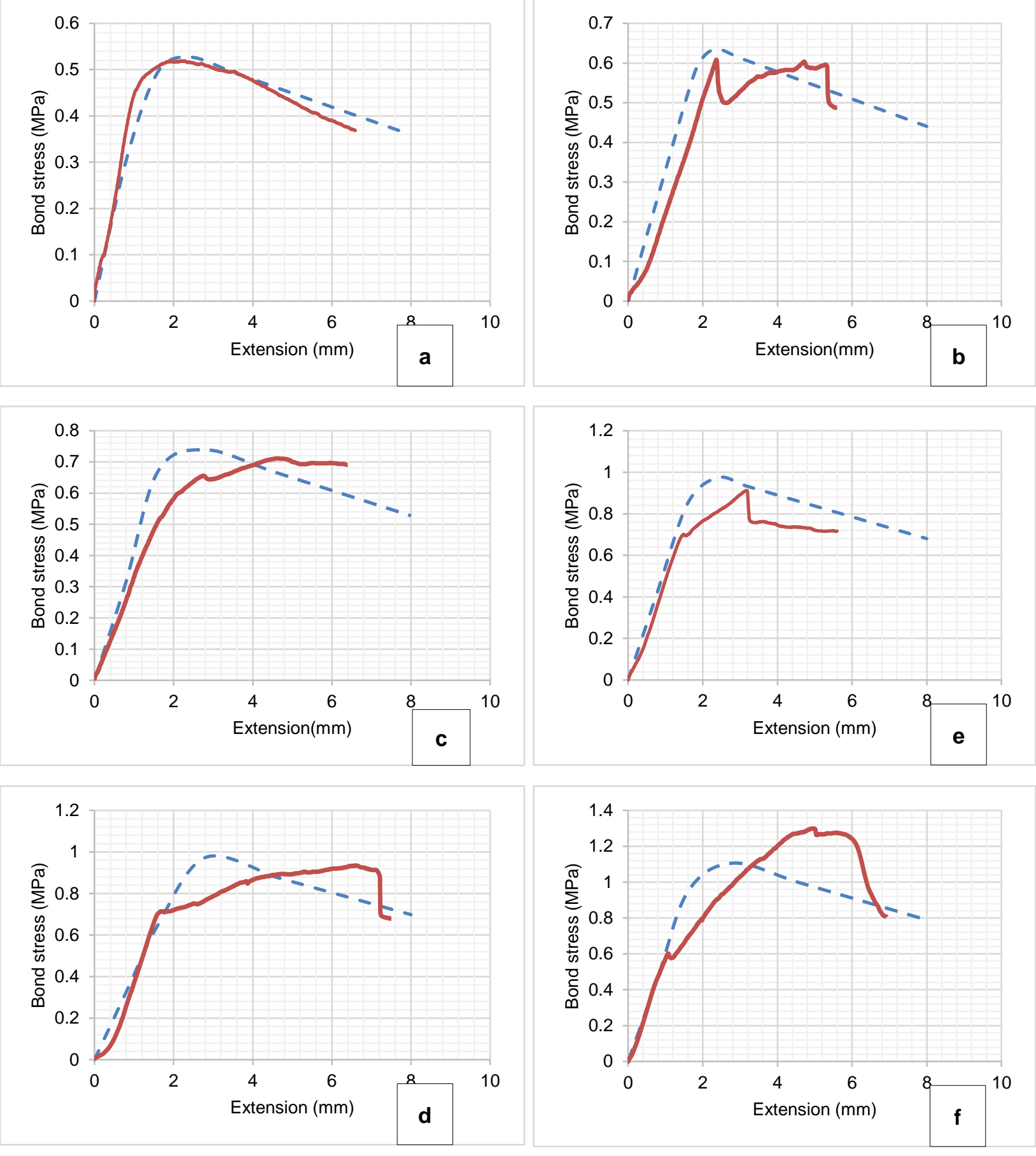

Key

Experiment

Finite Element Model ......

Figure 3.5: Bond (pull-out) stress behaviour between OPBF and concrete

(a) 1 fibre/tendon (b) 2 fibres/tendon (c) 3 fibres/tendon (d) 4 fibres/tendon (e) 5 fibres/tendon (f) 6 fibres/tendon 